Amelia Coulter

\author{
A Thesis \\ Presented to \\ The Faculty of Humboldt State University \\ In Partial Fulfillment \\ of the Requirements for the Degree \\ Master of Arts \\ In Psychology (Counseling)
}

May 2007 
SEXUAL SENSATION SEEKING AND SELF-EFFICACY'S RELATIONSHIP TO SEXUAL RISK TAKING BEHAVIOR

By: Amelia Coulter

Approved by Masters Thesis Committee:

Lou Ann Wieand, Major Professor

Date

Mark Harwood, Committee Member

Date

James Dupree, Committee Member

Date

Mark Harwood, Graduate Coordinator

Date

Chris Hopper, Graduate Dean 


\begin{abstract}
Research demonstrates that young adults typically score high on knowledge of safe sex practices. Unfortunately, knowledge about risk is often quite unrelated to practicing safer sex behaviors; and STD infection and HIV/ AIDS are increasing in young adult populations. Young adults are more uniquely at risk for developing sexually transmitted diseases because they change partners more regularly than other age groups, and believe in their own invulnerability to disease and trauma. The purpose of this study was to further identify factors that contribute to college students' decisions to engage in risky sexual behavior.

One hundred and sixty-seven young men and women ages 18 to 25 were recruited from a variety of majors at a northern California university. Participants filled out confidential online questionnaires composed of questions regarding sexual behaviors. The Sexual Sensation Seeking Scale (Kalichman, Johnson, Adair, Rompa, Multhauf \& Kelly, 1994) and the Sexual Self-Efficacy Scale (Rosentahal, Moore \& Flynn, 1991) were also included in the questionnaire.

Individuals who exhibited high sexual sensation seeking behaviors were found to score significantly higher on sexual risk. In contrast, sexual self-efficacy did not appear to be related to sexual risk. These unexpected results suggest new approaches to intervention/protection campaigns that will successfully target this age group.
\end{abstract}




\section{ACKNOWLEDGEMENTS}

There have been so many amazing people in my life who have contributed to this project and my journey to and through graduate school. I would like to start by thanking my family who have always supported and believed in me no matter what venture I have attempted. With their guidance and support I feel like I am capable of just about anything I set my mind to. I want to thank my parents for the countless phone calls and words of encouragement especially in the times that I wasn't sure If I would be able to complete this process. That includes my father's early morning messages “ This is your father. Get to work” that I usually let my answering machine pick up, I still heard you Dad.

I would also like to express my thanks and respect to Dr. Lou Ann Weiand for her continued belief in me throughout this project. She has been a great mentor and her enthusiasm and passion for her research has inspired me greatly. Even though she has traveled across the globe during the duration of this project she has always been just an email away.

Next I would like to thank my committee members, Dr. James Dupree and Mark Harwood for their participation in this project. Each faculty member that has been involved has had very different viewpoints and has in my mind added a great deal from their experience and unique standpoint.

My gratitude to George Bailey for spending countless hours in the computer lab making this survey possible, and being patient with those of us lacking in the technology field. 
Lastly I would like to thank all my friends who have supported me through the years and who have helped me through so much. A special thanks to Stephanie Haley, Nate Weinstein and Kathy Koeppen who went through this process by my side. We have shared the last few years stuck in classrooms together and I'm still not sick of you. I don't know how I would have gotten through this with out your humor, understanding and being able to vent to people who I have shared this unique experience with. Kathy we've gone through every step of this process together and I am so happy to be finishing at the same time as you, your friendship has meant so much to me. 


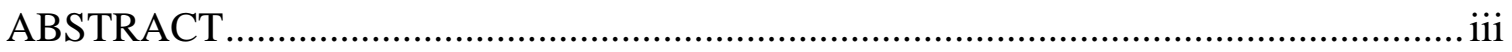

ACKNOWLEDGEMENTS .................................................................................. iv

TABLE OF CONTENTS ....................................................................................... vi

LIST OF APPENDICIES ………………………….............................................. viii

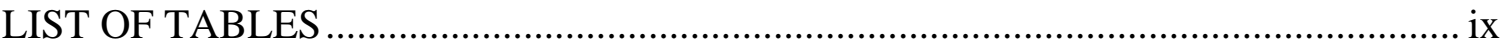

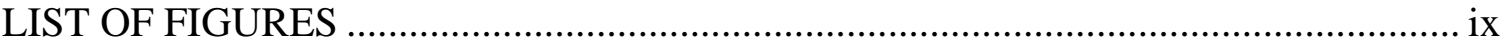

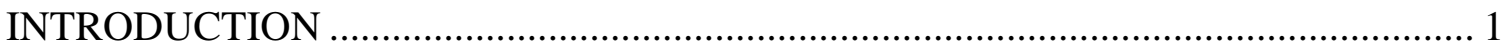

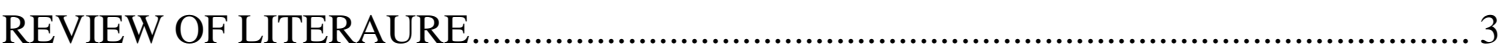

Young Adults and Sexual Risk Taking Behavior ...................................................... 3

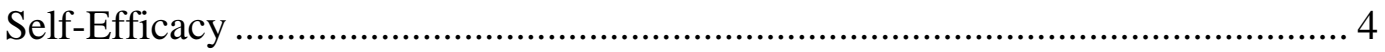

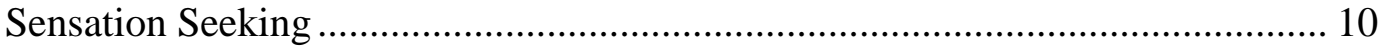

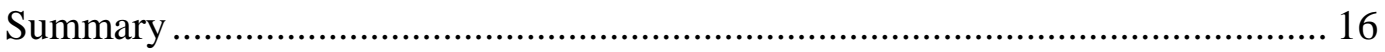

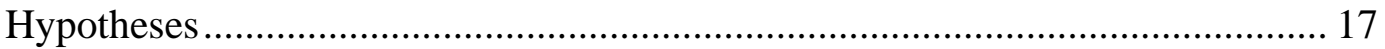

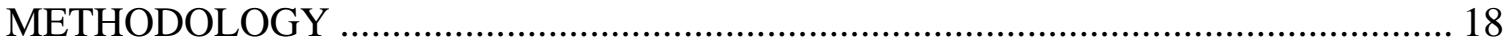

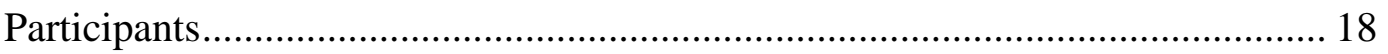

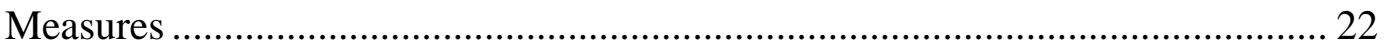

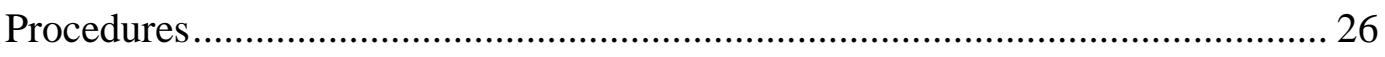

Risks, Benefits, and Management of Risks .......................................................... 28

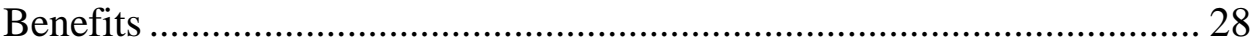

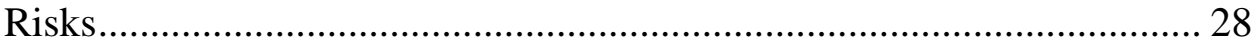

Management of risks.......................................................................... 29 


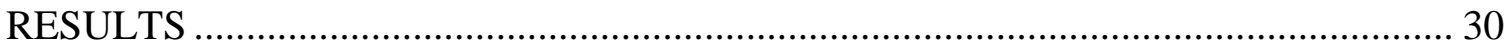

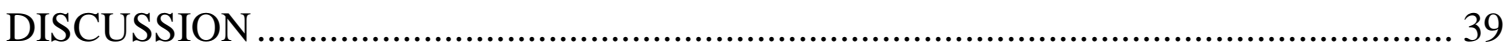

Limitations of the Study and Implications for Future Research ......................... 44

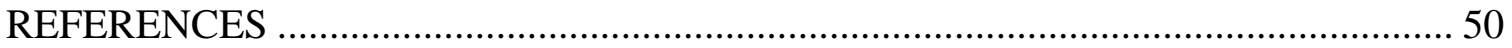




\section{LIST OF APPENDICIES}

Appendix

Page

A E-MAIL TO ADMINISTRATIVE ASSISTANTS ....................................... 56

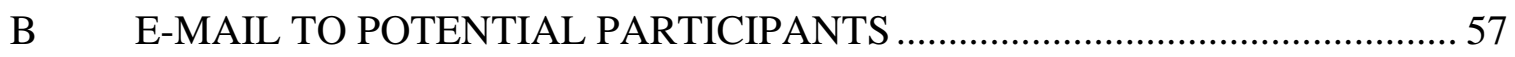

C SURVEY OF SEXUAL BEHAVIORS ......................................................... 58

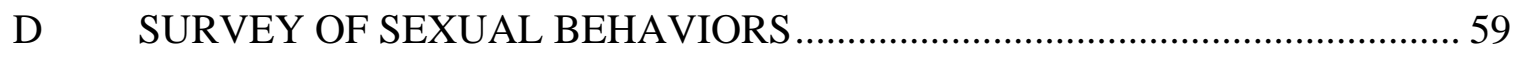

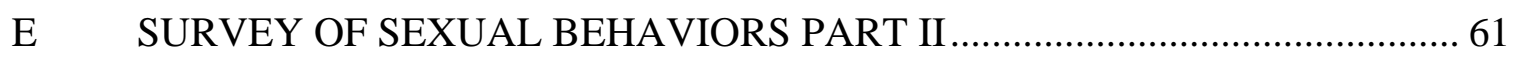

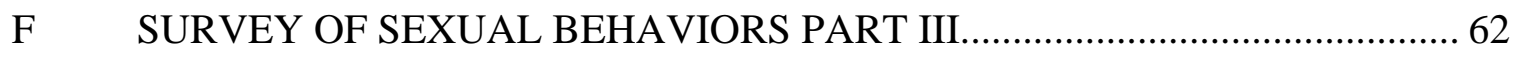

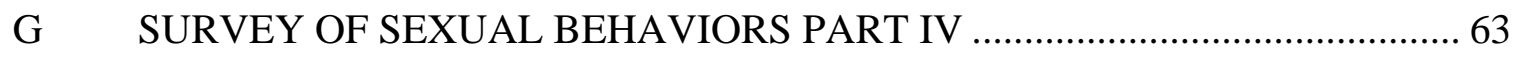

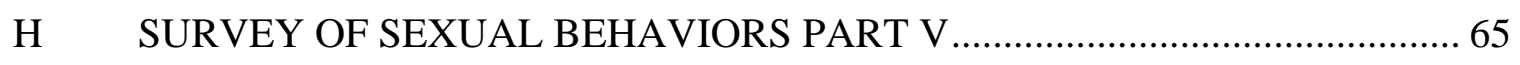

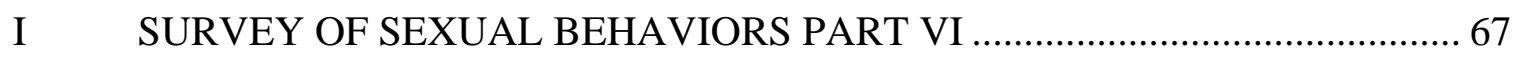

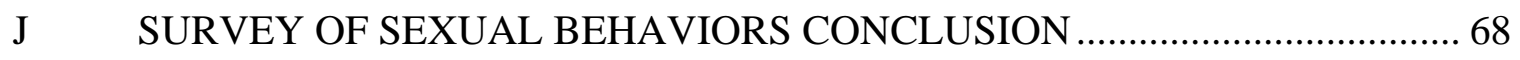

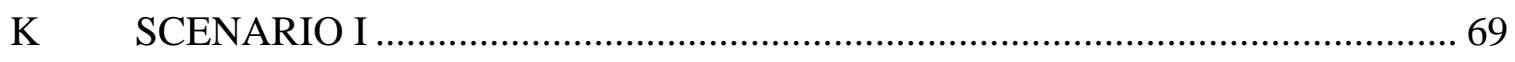




\section{LIST OF TABLES}

Table

Page

1 Frequency Distribution of Demographic Variables ........................................ 20

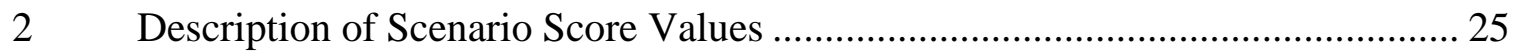

3 Correlation Matrix of Major Variables (Sexually Active Subjects, $n=113$ )....... 36

\section{LIST OF FIGURES}

Figure

Page

1. Safe Sex Score. Percentage of time condoms were used during actual intercourse events for the past three months as reported by the sexually active sample of students. 


\section{INTRODUCTION}

Intervention strategies have aimed to increase awareness of the dangers and risks associated with unsafe sex on college campuses by promoting and increasing knowledge and participation of safer sex practices. Unfortunately, an increase in awareness and availability of resources hasn't produced a significant decrease in risky sexual behavior (Arnold, Fletcher \& Farrow, 2002). College students generally engage in behaviors such as having sex with multiple partners and practicing unsafe sex that enhance their risk of Sexually Transmitted Diseases (STD’s) and the Acquired Immune Deficiency Virus (AIDS) (Sheer \& Cline, 1995). There is a need to understand more about what factors might be influencing this population's choice to engage in behavior that puts them at risk for contracting STDs and AIDS. In exploring new ways to look at what affects this population's sexual decision-making process we might be better able to tailor a prevention and intervention model that suit's the needs of this unique age group.

Having sex with multiple partners and not using contraceptives that protect against STD/AIDS aren’t the only risky behaviors in which college students engage. Experimenting with drugs and drinking excessive amounts of alcohol are also commonly associated with a college lifestyle. Having unprotected sex is correlated with other risky behaviors including drug and alcohol use. Risky sexual behavior has been identified in a number of studies as 1.) Having two or more sex partners in the previous three months, 2.) Having vaginal or anal intercourse without prophylactics that protect from STD and HIV infection, 3.) Engaging in sexual intercourse that involved blood contact in the past 
three months, 4.) History of STD infection and 5.) Having a history of injection drug using and or having a partner who has had a history of injection drug using (Kalichman, Simbayi, Cain, Cherry, Jooste \& Mathitit, 2005). Some researchers believe that certain personality traits influence these risk-taking behaviors, such as "sensation seeking” (Rosenthal \& Moore, 1993). Sensation seeking is characterized as consisting of four dimensions: thrill and adventure seeking, experience seeking, disinhibition and boredom susceptibility. Sensation seeking is a term that is often synonymous with people who engage in risk taking behavior and has been repeatedly associated with risky sexual behavior (Sheer \& Welch Cline, 1995).

Sexual self-efficacy is described as a person's belief that they can exert control over their motivation and behavior in a sexual situation (Bandura, 1994). Sexual self-efficacy is another factor that might contribute to a young person's decision to practice safe/ unsafe sex. Young women who have high sexual self-efficacy are linked to lower levels of sexual risk taking (Seal, Minichiello \& Omodei, 1997).

Sexual sensation seeking and sexual self-efficacy might be important contributing factors in the likelihood of participation in risky sexual behavior in college students. In studying the effects of these traits on sexual behavior in college aged populations, we will gain a better understanding as to what prevention/ intervention strategies might be more effective to promote safer sex practices on college campuses. 


\title{
REVIEW OF LITERAURE
}

\author{
Young Adults and Sexual Risk Taking Behavior
}

Although young adults currently account for a relatively small percentage of the diagnosed AIDS cases in the United States, according to the Center for Disease control (CDC) young people between the ages of 13 and 24 are at an increasing risk for HIV infection (CDC, 2003). Despite high levels of awareness regarding the avenues of transmission and dangers associated with HIV and other sexually transmitted diseases in the United States (Cooper, Shapiro, \& Powers, 1998), many young people continue to engage in sexual behaviors that place them at risk for contracting these diseases.

The majority of research findings among college students suggest that a high level of HIV and STD risk behavior is associated with inconsistent or lack of condom use, multiple lifetime sex partners, and alcohol and other drug use combined with sexual activity (Catania, Coates, Stall, Turner et al., 1992; Donenberg, Emerson, Bryant \& King, 2006; Lewis \& Malow, 1997). The Center for Disease Control (CDC), in the National College Health Risk Survey, indicated that 35\% of college students ages 18-24 had had six or more sexual partners in their lifetime, only 25\% reported consistent condom use with their partner, and $17 \%$ of college students polled had used alcohol or drugs during their last sexual encounter (CDC, 1997). Other studies have suggested that less than 10\% of college students report consistent condom use (Prince \& Bernard, 1998).

Intervention and prevention programs in public high schools have focused most of their attention on admonitions to abstain from sex, except for in monogamous 
relationships. (Kelly \& Kalichman, 1995; Peterson \& DiClemente 2000). Although abstinence will stop the incidence of HIV infections (Kelly \& Kalichman, 1995), this model greatly underestimates the complexity of sexual behavior and the difficulty many young people have in following these prescriptions.

In order to better tailor HIV/AIDS prevention and intervention models for young adults it's important to explore the impact of the psychological, physiological, behavioral, and emotional components that affect a young person's decision to engage in sexual behavior.

\section{Self-Efficacy}

The concept of self-efficacy originated from Albert Bandura’s (1977) social cognitive theory. This construct has since been applied to a number of important studies in health psychology and has contributed greatly to the study of HIV/AIDS prevention strategies. Bandura defines perceived self- efficacy as a way to achieve self-directed change.

Perceived self-efficacy is concerned with people’s beliefs that they can exert control over their motivation and behavior and over their emotional environment. People's beliefs about their capabilities affect what they choose to do, how much effort they mobilize, how long they will persevere in the face of difficulties, whether they engage in self-debilitating or self-encouraging thought patterns, and the amount of stress and depression they experience in taxing situations (Bandura, 1990 p.9). 
Bandura recognized the importance of applying self-efficacy to personal management of sexuality in young adults, and hypothesized that just providing people with information on the dangers of HIV and AIDS will not suffice in the face of difficult sexual decision making. In his book Self-Efficacy: The exercise of control, Bandura (1997) acknowledged the difficulty in accesing knowledge under conditions of interpersonal pressure and social persuasion:

In these interpersonal predicaments, the sway of allurements, heightened sexual arousal, desire for social acceptance, coercive pressures, situational restraints, and fear of rejection and personal embarrassment can override the influence of the best informed judgment (p.180).

Bandura explained that the weaker the perceived self- efficacy or ability to utilize personal control in the face of such pressure, the increased likelihood of participation in early or risky sexual behavior.

Although historically young adults haven't been the primary targets for campaigns aimed at STD or AIDS prevention, in recent years this age group has been recognized to be more susceptible to high-risk behaviors than once believed (Lewis \& Malow 1997). Since the HIV epidemic began, more and more cases of heterosexual young adults contracting this disease have been reported (Kelly, 2001). According to statistics from the Center for Disease Control and Prevention in 2003 in the U.S, “An estimated 7,081 young people were living with AIDS, a 37\% increase since 1999 when 5,159 young people were living with AIDS” (CDC, 2005 p.27). Young people were defined as those between the ages of 13 and 24. It's important to note that these statistics 
reflect the numbers of young people living with AIDS and do not count those who are living with the HIV virus. Many who are living with HIV may be unaware that they have the virus and may be unknowingly spreading it to others.

Research suggests that certain populations are susceptible to HIV and AIDS infection because of certain behavioral characteristics that make them more vulnerable (Kelly, 2001). Among college students there are several factors that might put this population at risk. College-aged students are prone to participate in situations that have been acknowledged as increasing the risk of contracting the HIV virus such as having multiple partners, being in noncommittal sexual relationships, not using contraceptives such as condoms that help to reduce transmission of this disease, and using drugs or alcohol during sexual intercourse which has been linked to impaired judgment in choosing sexual practices with lower risks (Kelly, 2001; Lewis \& Malow, 1997).

Although recent studies have shown that college students have an increased knowledge about the AIDS virus due to an increase in campaigns and classes aimed at this age group, many young people do not believe that they are personally at risk (Fisher, Fisher, Misovich, Kimble, \& Malloy, 1996). By thinking that they're not personally at risk these young adults inevitably cease to take the necessary precautions as seriously as they should. This mentality has also been likened to those living in more rural towns that had once believed that AIDS was only a risk for those in the larger metropolitan areas. It's now known that AIDS does not discriminate between gay or straight, young or old or between rural or urban life (Kelly, 2001). 
Why are young people continuing to put themselves at risk for such diseases even though countless campaigns and prevention strategies have bombarded this group with knowledge of the dangers associated with HIV and AIDS? Many proponents of selfefficacy theory believe that simply having provided information on the dangers of health impairing habits is not enough, Bandura (1990) notes that information alone has not stopped people from smoking despite the unarguable link to cancer nor has nutritional information contributed to great decrease in cardiovascular disease. It has not slimmed the obese and he goes on to state that information and scare tactics alone will, "certainly not make the sexually active celibate and impel intravenous drug users to renounce drugs, which are the two major transmitter modes for the AIDS virus” (p.9). Self- efficacy theory suggests that in addition to information people need to be given the resources and learn how to alter these risky habits and most importantly to feel confident in their ability to make effective changes in their behaviors.

Many studies have been conducted to test Bandura’s theory of self-efficacy, however, results have been mixed and often difficult to interpret. In 1998, Forsyth and Carey conducted a meta-analysis, and took a closer look at more than 400 published articles measuring HIV risk and self-efficacy theory and analyzed their findings They have concluded that although HIV risk and self-efficacy theory has yet to provide any concrete and clear connections, relinquishing the possible link between these two constructs would be very premature and that the problems associated with past research on this subject is due in large part to flawed measurement and operationalization of efficacy beliefs in HIV research. Among many recommendations for future research, 
Forsyth and Carey (1998) believe that measures of global self-efficacy tend to be ambiguous and that certain groups including college students tend to perform poorly on these collective tests. They believe that it is time that self-efficacy interventions focus more on self-efficacy in domain specific areas such as in the sexual decision making process. A person might score highly on a global study of self-efficacy but when faced with a specific real life challenging scenario might answer differently and have less faith in their ability to successfully maneuver through a difficult situation.

In a study conducted in 2001 by Murphy, Stein, Schlenenger, Maibach, \& The National Institute of Mental Health Multisite HIV Prevention Trial Group, researchers tested the efficacy of an HIV preventive intervention with several high-risk populations including men and women recruited from STD clinics and community-based health organizations in various metropolitan areas. This study focused on comparing a selfefficacy measure based on Bandura’s conceptualization of the two factors that contribute greatly to self-efficacy: the situation or scenario people find themselves in, and the graded difficulty of the behavior that person has to perform to be safe. Findings from this study support that self-efficacy has a strong impact on health-changing behaviors and that assessing self-efficacy in a situation-specific, level-specific manner allows a more precise look into the complicated decision-making process surrounding the practice of safe sex.

A recurrent theme in the assessment of self-efficacy theory as a possible explanation for risky sexual behavior is that of perceived ability to carry out an action and the ability to actually carry out that action. Rosenthal, Moore, and Flynn (1991) investigated the relationship between self-perceptions, including sexual self-esteem and 
sexual self-efficacy of 18-year-old males and females and their relationship to sexual risk taking. Results of their study showed that most of the respondents in this study felt relatively confident in their ability to engage in a wide range of sexual behaviors including purchasing condoms and discussing their use or delaying sexual intercourse until protection was available. However, these researchers are also very quick to point out that there is a large inconsistency in what these adolescents believe they can do and what they actually do. Another finding was that respondents recorded higher levels of confidence in discussing using condoms or contraceptives with a potential partner as means of pregnancy prevention as opposed to discussing condoms/ or contraception as means of safe sex. The authors explain the latter to be seen as embarrassing because it could be viewed as negatively reflecting on their partner’s past sexual history (Rosenthal, Moore \& Flynn, 1991).

Overall, the Rosenthal et al. study (1991) did suggest that teaching adolescents strategies to feel more confident and assertive in their ability to practice safe sex and or to refuse certain sexual activities may lead to safer sexual practices. Because these links were not as clear as one might have expected, it's important to note that these decisions are multifaceted and depend on a multitude of factors, confidence being important, but not by any means a sole, contributor.

Wulfert and Wan (1995) conducted three studies on how well the health belief model, the theory of reasoned action, and Albert Bandura's social cognitive theory were capable of explaining heterosexual persons' sexual risk taking. These researchers found that individuals' decisions to use condoms depends on three key elements of social 
cognitive theory ; the expected personally relevant consequences of condom use, whether one perceives condom use as a behavior approved by ones peers, and beliefs that one will be able to use condoms consistently given the specific emotional and interpersonal circumstances of one's life. These variables were identified in three separate studies with different populations and predicted intentions to use condoms in both a cross-sectional design and self reported condom use in a longitudinal design. Because these key factors are the main constituents of self-efficacy theory they provided support for social cognitive theory as a major framework for better understanding sexual risk.

Sensation Seeking

Marvin Zuckerman first explored a theoretical model of sensation seeking in 1969. He continued research on this topic and wrote his first book on this theory in 1979, Sensation Seeking: Beyond the optimal level of arousal. This theoretical model had begun as an explanation of an individual's optimal level of cortical arousal; that is, sensation seekers are motivated to engage in activities that increase their level of arousal. He later rejected this optimal arousal basis for sensation seeking and reduced arousal to a secondary role. He now hypothesizes that sensation seeking is a general sensitivity to reinforcement that may reflect levels of catecholamines and their enzymes (Zuckerman, 1994). This trait has further evolved in the last thirty years of research to correlate with a variety of new findings including: psychopathology, mood, cognition activity, and social behavior including risk taking behavior, sexual experiences, and drug and alcohol use. Zuckerman described sensation seeking as: 
“A trait defined by the need for varied novel, complex and intense sensations and experiences, and the willingness to take physical, social and legal risks for the sake of such experience” (p. 27).

Sensation seeking is a multi-dimensional construct that includes four components: thrill and adventure seeking, experience seeking, disinhibition, and boredom susceptibility (Zuckerman, 1994). Sensation seeking has been associated with a number of high-risk activities including extreme sports, reckless driving, driving under the influence, gambling, drug abuse, and risky sexual behavior (Zuckerman \& Kuhlman, 2000). In terms of risky sexual behavior and sensation seeking Zuckerman has stated that, "High sensation seekers tend to engage in a greater variety of sexual behaviors with a greater number of partners than low sensation seekers” (Zuckerman, 1994, p.144). Sensation seeking offers a motivational explanation for sexual risk behavior; if these motivations outweigh a person's intent to use contraception they seriously risk the threat of STD and HIV infection.

Individuals high on this dimension are thought to be more sensitive to reward than punishment clues (Gray, 1990). Similarly, high sensation seekers are more likely to engage in risky behavior to seek out or enhance pleasure, whereas low sensation seekers might participate in risky behavior for different reason, for instance to be liked or fit in with one’s peers (Cooper, Shapiro \&Powers, 1998). High sensation seekers should then be more influenced by the short-term benefits of a risky behavioral choice and should be less influenced by its potential long term costs (Cooper, Wood, Ocrutt \&Albino, 2003). 
Consistent with these descriptions is the relationship sensation seekers have with a wide range of high-risk activities as will be discussed as follows.

In 1990 Fisher and Misovich conducted a study that supports Zuckerman’s findings when they investigated the relationship between high risk sexual behaviors and sensation seeking among homosexual and heterosexual college students. Results indicated that sensation seeking was positively correlated with the number of sexual partners including unfamiliar sexual partners reported by both homosexual and heterosexual college students. Fisher and Misovich concluded, “sensation seekers probably do constitute a high risk group for AIDS, owing to their greater number of sexual partners and generally low level of concern about incurring the diseases” (1990, p.57). Newcomb and McGee (1991) also identified similar patterns of increased sexual events and relationships between individuals scoring higher on sensation seeking, especially for those who reported more disinhibition and boredom susceptibility.

A quantitative review of 53 studies that focused on personality and sexual risk taking (identified in this study as number of partners, unprotected sex, and high risk sexual encounters, e.g sex with a stranger) found that sensation seeking accounted for $64 \%$ of the effect size (Hoyle, Fejfar \& Miller, 2000). Some of the articles they reviewed and their findings are described more closely in the following summaries.

In a 1995 study by researchers Sheer and Cline, focus was given to individual differences in the predisposition of sensation seeking as a possible explanation for the failure of college students to engage in safe sex behaviors. This study found that AIDS knowledge was unrelated to sexual behavior and that students who were found to be rated 
as "high sensation seekers" engaged in riskier sexual behavior than did moderate and low sensation seekers (Sheer \& Cline, 1995). These researchers went on to suggest that because of the above stated findings AIDS prevention campaigns aimed at this age group might benefit in targeting appeals to audiences of both high and low sensation seeking groups.

Horvath and Zuckerman (1993) considered factors that might account for the association between sensation seeking and risky behaviors and found that differences in risk appraisal between high and low sensation seekers do not account for differences in a high risk activity; high sensation seekers evaluate the activity as less risky and feel less anxiety in these activities than low sensation seekers. These findings suggest that high sensation seekers view novel activities as less risky than do their low sensation seeking counterparts.

In summary the quantitative review of personality and sexual risk taking investigated by Hoyle, Fejfar \& Miller (2000) found that sensation seeking predicted all forms of sexual risk taking covered by their review, including number of partners, unprotected sex, and high risk sexual encounters. Hoyle, et al., suggest the process by which risk appraisal and sensation seeking influence risky behavior to be a complex process that might be better understood by more research on mediators of the sensation seeking risk taking relationship and its biological mechanisms.

Other studies have sought to link components related to sensation seeking that affect sexual risk taking behavior. One such study examined the relationship between sensation seeking and evaluation of risk and attractiveness of potential partners. Results 
from this study suggest that compared with low sensation seekers, high sensation seekers rated potential partners as more attractive, less likely to possess an STD, and were more likely to want to date the individual described (Henderson, Hennessy, Barrett, Curtis, McCoy-Roth, Trentacoste \& Fishbein, 2005). High sensation seekers also rated their likelihood of acquiring an STD infection as lower than did the low sensation seekers (Henderson, et. al.).

Another study found strong associations between sexually active high school students who scored high on both sensation seeking and impulsive decision-making measures (Donohew, Zimmerman, Cupp, Novak, Colon, \& Abell, 2000). These students were found to score higher on measures involving health risks including not using contraceptives and higher numbers of sexual partners. Sensation seekers were also found to have been significantly related to having had experiences using alcohol and or marijuana before sex in the last year. The only variable in this study that was not found to be significantly related to high scores on sensation seeking and impulsive decisionmaking scales was saying no to sex. Having unwanted sex under pressure was found to be related to impulsive decision-making but not to sensation seeking.

Alcohol use has long been associated with college settings and many studies have sought to explore alcohol consumption as a mediating variable in some college student's failure to practice safe sex (Gullettte \& Lyons, 2005; Kalichman \& Cain, 2004; Katz, Fromme, \& D’Amico, 2000). In fact Kalichman and Rompa (1995) describe a sexual sensation seeker to be a person who is prone to engage in attending parties, drinking 
excessively, using illicit substances, and engaging in sexual intercourse with a variety of partners.

In a review article that focused on examining studies in the past 10 years that link drinking and risky sex in college students, findings suggest that although drinking was strongly related to the decision to participate in "indiscriminate forms of risky sex (having multiple or casual sex partners), it was inconsistently related to protective factors (condom use)” (Cooper, 2002). Although future efforts that might aim to reduce alcohol use in sexual situations might actually help to prevent some participation in risky sexual behavior, students might need other interventions aimed at the use of protective factors such as the use of condoms

Many studies have linked sensation seeking with risky behavior including substance use and risky sexual behavior. However, the original Sensation Seeking Scale included many items that pertained to both behaviors; so many questions about substance use might have had an illusionary correlation between sensation seeking and risky sexual behavior. Researchers Kalichman, Johnson, Adair, Rompa, Multhauf and Kelly (1994) developed a measure specifically for the purpose of measuring sensation seeking specific to sexual behavior, the Sexual Sensation Seeking Scale. Sexual sensation seeking is operationalized as "the propensity to attain optimal levels of sexual excitement and to engage in novel sexual experiences” (Kalichman, et. al., 199). The development of this scale was found to be consistently linked to high risk sexual practices that could not be accounted for by substance use (Kalichman \&Rompa, 1995). 
Summary

\begin{abstract}
Albert Bandura's theory of self-efficacy and Marvin Zuckerman's theory of sensation seeking have both contributed greatly to the study of sexual risk. However, much is yet to be understood about the complicated process that governs an individual's decision to engage in unsafe sexual behavior. Numerous studies have examined the relationship between both self-efficacy and sensation seeking with sexual risk. Relatively few studies have examined these constructs in conjunction with one another to account for any significant attribution to sexual risk and even fewer studies have sought to understand the relationship between self-efficacy and sensation seeking.

Self-efficacy theory and sensation seeking theory have been linked to many different concepts including health and risk related behavior. Because these concepts are so global, measures for each of these theories have been developed to look strategically at the sexual situation. Both the Sexual Self-Efficacy Scale (Rosenthal \& Moore \& Flynn, 1991) and the Sexual Sensation Seeking Scale (Kalichman, et. al., 1994) have been developed to look at the specific connection these theories hold in sexual situations to better measure the their impact on sexual risk. These scales along with a measurement of sexual risk and a behavioral scenario that's intended to measure self-efficacy in the context of a difficult sexual situation were utilized in this study to examine what affects a young adult's decision to engage in risky sexual behavior. These findings might help to provide important implications for tailoring prevention and intervention models for this age group.
\end{abstract}




\section{Hypotheses}

1.) Individuals exhibiting high sexual sensation seeking traits will score higher on sexual risk taking.

2.) Individuals who score low on sexual self-efficacy will score higher on sexual risk taking.

3.) Sexual sensation seeking will be negatively correlated to sexual selfefficacy.

4.) Those individuals receiving scenarios with a high stress condition will choose to participate in riskier sexual behavior than those receiving a low stress condition.

5.) Those individuals receiving scenarios with self-debilitating thought patterns will choose to participate in riskier sexual behavior than those receiving scenarios with self-encouraging thought patterns.

6.) There will be an interaction between stress and thought pattern conditions. Those receiving both high stress and self-debilitating thought patterns will choose to participate in the most risky sexual behaviors. 


\section{METHODOLOGY}

\section{Participants}

Participants consisted of male and female students from a Northern California University. Students received the survey of sexual behaviors via e- mail from the administrative assistants in their departments. The participating departments consisted of a variety of majors on campus: psychology, business, environmental sciences, engineering, theater, and the department of communication. Participation in this survey was voluntary.

A total of two hundred and twenty-five participants responded to the on- line survey. Fifty-eight respondents had to be screened out because their age was over the desired age for this study (18-25) leaving a total of 167 participants within the desired age range. One hundred and twenty-one (72.5\%) of the participants were female and 46 (27.5\%) of the participants were male. The mean age of participants was 21.2 years of age. One hundred and thirty-three (79.6 \%) of the participants classified their ethnicity as “white”, 11 (6.6\%) classified their ethnicity in the "other” category, 9 (5.4\%) were “Latino”, 4 (2.4\%) were “Asian”, 4 (2.4\%) were “Filipino”, 3 (1.8\%) classified themselves as "black or Afro-American" and 1 person (.6\%) endorsed the "Native American Indian” category.

Of the 167 participants, 133 (79.6\%) identified themselves as heterosexual, 19 (11.4\%) identified themselves as bisexual, 9 (5.4\%) participants put “other”, and 6 (3.6\%) classified themselves as homosexual. One hundred and nine (65.3\%) of the 
participants were single and had never been married, 38 (22.8 \%) were married or living with their partner, 20 (12\%) endorsed the “other" category.

One hundred and thirteen (67.7\%) of the participants considered themselves to be sexually active that is, participating in sexual intercourse, oral, genital or anal sex on a regular basis. Fifty-four (32.3\%) of the participants did not consider themselves to be sexually active at the time (See Table 1 ). 
Table 1

Frequency Distribution of Demographic Variables

\section{Frequency}

Variable

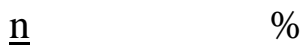

Age

$18-25$

167

26 and over*

58

*Participants who were over the age of 25 were screened out from the rest of demographic info because they were over the desired age range

Gender

Male

121

72.5

Female

46

27.5

Ethnicity

White

133

79.6

Other

11

6.6

Latino

9

5.4

Asian

4

2.4

Filipino or Pacific Islander

4

2.4

Black/ Afro American

3

1.8

Native American Indian

1

.6 
Sexual Orientation

Heterosexua

Bisexual

Other

Homosexual

Relationship Status

Single

Married or Living with Partner

Other

Sexual Activity

Sexually Active

Not Sexually Active
133

79.6

19

9

6

3.6

109

65.3

38

22.8

20

12.0

113

67.7

54

32.3 
Measures

A self- report anonymous questionnaire was entered on -line containing measures on sexual sensation seeking, sexual self -efficacy and sexual risk taking behavior, including beliefs about alcohol and sex. In addition participants were randomly assigned one of five behavioral scenarios and answered questions regarding the likelihood of engaging in unsafe sex in that situation.

Sexual sensation seeking, defined as the, “propensity to attain optimal levels of sexual excitement and to engage in novel sexual experiences” was measured by the Sexual Sensation Seeking Scale (SSS) (Kalichman, Johnson, Adair, Rompa, Multhauf \& Kelly, 1994). The SSSS contains 11 Likert scale items that are measured on a four-point scale. The scale ranges from 1 (not at all like me) to 4 (very much like me), with a minimum score of eleven and a maximum score of 44 . This instrument was first tested with106 homosexual men with a reported internal consistency of 0.75. Kalichman and Rompa (1995) went on to further validate this scale on 98 men and women. The internal consistency was 0.81 , and a 3-month test revealed 0.73 re-test reliability. Beck, Thombs, Mahoney and Fingar (1995) further validated this instrument on 900 heterosexual college students and reported an internal consistency of 0.81 .

The Sexual Self-Efficacy Scale (SSE) is concerned with measuring people’s beliefs that they have the ability to exert personal control in sexual situations. This scale was based on the Sexual Self-Efficacy Scale in Erectile Functioning developed by Libman, Rothenburg, Fichten and Amsel (1985). Rosenthal and Flynn (1991) then added items to this scale to check for item discrimination, difficulties of comprehension 
and ambiguity to make the scale appropriate for both sexes. The current scale consists of 20 items that consist of a series of sexual activities. Subjects are asked whether or not they think that they could do each activity. For those activities they could do they are asked to rate their degree of confidence in their ability to do so on a five-point scale. The scale ranges from 1 (very uncertain) to 5 (absolutely certain). The activities the respondent categorizes as "not able to do" are included as zero confidence items (See Appendix I).

Participants were also assigned one of five behavioral scenarios constructed by the researcher. The scenarios were loosely based upon Albert Bandura's definition of perceived self-efficacy (Bandura, 1990). These scenarios presented the participant with a sexual situation that they were asked to respond to as if they were actually faced with this situation. Each scenario began with the same description of events. Towards the end of the scenario two independent variables were manipulated. The first variable was either a high stress or low stress condition. The high stress condition was indicated by a partner's negative response when asked if they have a condom, “they sharply reply, No I'm safe. We don't need a condom”. The low stress condition was indicated by a gentler response by their partner when asked if they had a condom, “they kindly reply, “No I don’t have one either. What would you feel most comfortable doing now?” The second variable was whether or not the scenario included self-debilitating or self-encouraging thoughts. Selfencouraging thoughts were identified as "You're still feeling concerned and are taking all your feelings into account. You know that this is your decision to make and that your partner will understand.” Self - debilitating thoughts were identified as “you're still 
feeling concerned and unsure but now you're worried you're killing the mood if you bring it up again and you're fearful that you're offending you're partner. You don't want them to think you're not interested.”

In total there were 5 different scenarios. The first scenario incorporated the high stress condition with the self-debilitating thought. The second scenario incorporated a high stress condition with self-encouraging thought. The third scenario included low stress condition and self-encouraging thought. The fourth scenario included the low stress condition coupled with a self- debilitating thought. The fifth or final scenario incorporated neither variable in order to serve as a control.

Participants were then asked to respond to the scenario as honestly as possible and choose the response that best represented what they would most likely do in this situation. The responses were arranged randomly but scored as a Likert scale in increasing order of risk (See Table 2). The responses include, "have penetrative sex without a condom”, “not have sex”, “continue “hooking up” but not have penetrative sex", "ask my partner to purchase a condom and then have sex" or "purchase a condom and then have sex.” Participants were then be asked how confident they were in this 
Table 2

Description of Scenario Score Values

What would you most likely do in this situation?

$\begin{array}{ll}\text { Values } & \text { Answers } \\ 1 & \text { I would probably not have sex. } \\ 3 & \text { I would probably purchase a condom and then have sex } \\ & \text { I would probably ask my partner to purchase a condom } \\ 4 & \text { and then have sex. } \\ & \text { I would probably continue "hooking up" but not have } \\ & \text { penetrative sex. } \\ & \text { I would probably have penetrative sex without a } \\ & \text { condom. }\end{array}$

How confident are you that this would be your decision?

$\begin{array}{ll}\underline{\text { Values }} & \underline{\text { Answers }} \\ 1 & \text { Extremely } \\ 2 & \text { Very } \\ 3 & 50: 50 \\ 4 & \text { Somewhat } \\ 5 & \text { Not at all }\end{array}$


decision, in descending level of confidence from "Extremely", "Very”, “50:50", "Somewhat" or "Not at All".

\section{Procedures}

Participants were recruited from a variety of departments from the three major colleges at Humboldt State University. The department of communication and theater department from the College of Arts Humanities and Social Sciences participated in the survey. The Business department from the College of Professional Studies and the Psychology, Environmental Sciences, and Engineering departments from the College of Natural Resources and Sciences all participated in this survey. Administrative assistants in the above mentioned departments were sent an e-mail describing the project (Appendix A) and requesting bulk e-mails be sent out to their students notifying them of this survey.

Students willing to participate were able to link to the questionnaire from this email (Appendix B), which briefly described the project, and explained that participation was completely voluntary and if they wished to quit at any time, they could. Participants were than notified that any information obtained through the questionnaire would be kept completely anonymous. There was no way for anyone to track the address from which the survey was accessed. This survey took participants approximately twenty minutes to complete.

Prior to accessing the questionnaire participants were notified of the sensitive nature of this study and given information on local STD/AIDS testing centers 
(Appendix C). After reading this description interested participants who were over 18 were able to access the questionnaire. Once the participants gained access to the questionnaire (Appendices D- I) they were given directions for answering the questions (Appendix D) and were again assured that all the information obtained would be completely anonymous. Once they finish the questionnaire they clicked on a "submit survey” button and their answers were sent to an e- mail address. When they hit the "submit survey" button their answers went directly to an e-mail address as numerals and were not retrievable from the address from which they were sent.

Once students completed and submitted their surveys they were thanked for their participation in this research and given information on how to contact the researcher's supervisor and the appropriate web link if they would like to be able to attain a full summary of the anonymous answers that were obtained and a brief description about the results of this study (Appendix J). To assure that students who voluntarily participated didn't feel in any way uncomfortable about the questions that they answered, they were provided with information on anonymous HIV testing and counseling services in the community.

It should be noted that this research was embedded in a larger longitudinal study on sexual behavior and not all the data collected from this survey were analyzed at this time. Demographic information (Appendix D), the Sexual Sensation Seeking Scale (Appendix E), the sexual behavioral scenario's (Appendix K), questions that made up the Sexual Risk Measure (Appendix G, questions 3, 12-17) and the Sexual Self-Efficacy Scale (Appendix I) were all analyzed in this study. In addition information on whether or 
not participants considered themselves to be sexually active (Appendix G, question 1) the numbers of sexual partner's (Appendix G, question 4), drinking and drug use during sex (Appendix G, question 3) and information on HIV testing (Appendix G, question 7) were utilized for additional analyses.

Once all of the raw data from this survey were collected and analyzed, it was saved in a locked file drawer and will be saved for five years in case there are any questions regarding the study. Following this amount of time data will be shredded and destroyed

Risks, Benefits, and Management of Risks

Benefits

A potential benefit of this study was for participants to attain new knowledge about several factors and their contribution to college students' decisions to engage in sexual behavior. This new understanding of the factors that mediate these important health decisions provided new information for prevention and intervention strategies aimed at increasing safe sex on college campuses. A potential benefit in just completing these questionnaires was that college students might self-reflect on some of their past sexual decision making processes and re-evaluate future decisions.

Risks

A potential risk to this study was the issue of anonymity. When filling out questionnaires concerned with personal information it was important that the participant feel confident that their answers would not be identifiable or seen by others participating 
or working with this study. Another potential risk is because of the sensitive nature of this study some participants might have started thinking more about their past and present sexual experiences and their personal risk of STD/HIV infection. Also, if any of the participants have had past traumatic experiences this study may have heightened the awareness of or brought back memories of, this could be a potentially negative experience for the participant and be an associated risk of participation in this study. Management of risks

In order to manage the potential risks associated with this study it was necessary to make sure that the study was anonymous and that no identifiable characteristics were included on the questionnaire. This is why the researcher had to put the study on-line, so that all identifiable information would be kept completely anonymous. After participants submitted their answers to an e-mail address they were anonymously sent as numerals and researchers will be unable to detect their origins. Because participants were able to access the questionnaire on-line they also had the option of filling out the questionnaire in the privacy of their own homes to assure that their answers wouldn't be seen by others. After participants had completed the questionnaire, information was provided on both counseling services provided by the university as well as numbers and addresses of places in the community that provide anonymous testing for STD's and HIV. It was reiterated before participation that participation is voluntary and if anyone felt uneasy or unable to take part in this study that they could withdraw or terminate participation at any time with no consequences or questions asked. 


\section{RESULTS}

The primary goal of this study was to examine the association between sexual self-efficacy and sensation seeking on sexual risk taking behavior. Out of the 167 participants, 113 considered themselves to be sexually active, approximately $67.7 \%$. Analysis for the first three hypotheses was performed solely on the responses of those who considered themselves to be sexually active. The last three hypotheses were tested, using the responses of all participants. Two additional variables, numbers of partners and having sex while drinking or using drugs were analyzed to see how they related to sexual sensation seeking. These variables were tested using the data collected from the participants that considered themselves to be sexually active.

A composite risk score (the Sexual Risk Measure) was calculated by identifying the variables in past studies that demonstrated a risk of HIV or STD infection. These variables were 1 . having had more than one sexual partner in the past year, 2 . having sexual contact that could result in blood contact (i.e., having had vaginal or anal intercourse without a condom), 3. having injected drugs into or under your skin or 4. having a partner who has injected drugs into or under their skin. Having answered yes to any of these questions resulted in a composite risk score of 1-4, all of which were considered high risk. Participants who answered no to all four questions received a score of 0 and were not considered high risk.

Out of the participants who considered themselves to be sexually active, ninetyfour participants or $87 \%$ were considered high risk and received a composite risk score of 
1 through 4 . Only 14 participants (13\%) received a score of 0 and were considered low risk. Forty-six participants (42.6\%) received a composite risk score of 1 . Forty participants (37\%) received a composite risk score of 2, 7 participants (6.5\%) received a composite risk score of 3 and 1 participant (.9\%) received the highest composite risk score possible, 4 . The composite risk score mean for sexually active students was 1.4 with a standard deviation of .83.

Sexually active participants were asked how many times in the past three months they had vaginal intercourse with a condom. The mean for this group was 8.37 with a standard deviation of 15.62. Sexually active participants were also asked how many times in the past three months they had vaginal intercourse without a condom. The mean for this group was 23.3 with a standard deviation of 25.52. A safe sex score was calculated for each person using a ratio of number of times the person had sex with a condom divided by the total number of times they had sex in the past three months (See Figure 1). A total of 48 (42.5\%) of the sexually active participants reported not using condoms at all in the past three months, and 18 (15.9\%) participants reported using condoms every time they had sex in the past three months. The mean percent for the safe sex score was 34.2 $\%$.

Out of the participants who considered themselves to be sexually active, only 15 participants or $13.3 \%$ believed that they were at risk for contracting the HIV virus, 98 participants (86.7\%) did not feel like they were at risk of contracting the HIV virus. Sixty-two percent of the sexually active participants had reported being tested for the HIV virus, although the time or frequency of this testing was not recorded. Thirty-six 
(21.6\%) of the total sample felt that they were at risk for contracting an STD. Seven people out of the total sample actually recorded having been diagnosed with an STD in the past year. 


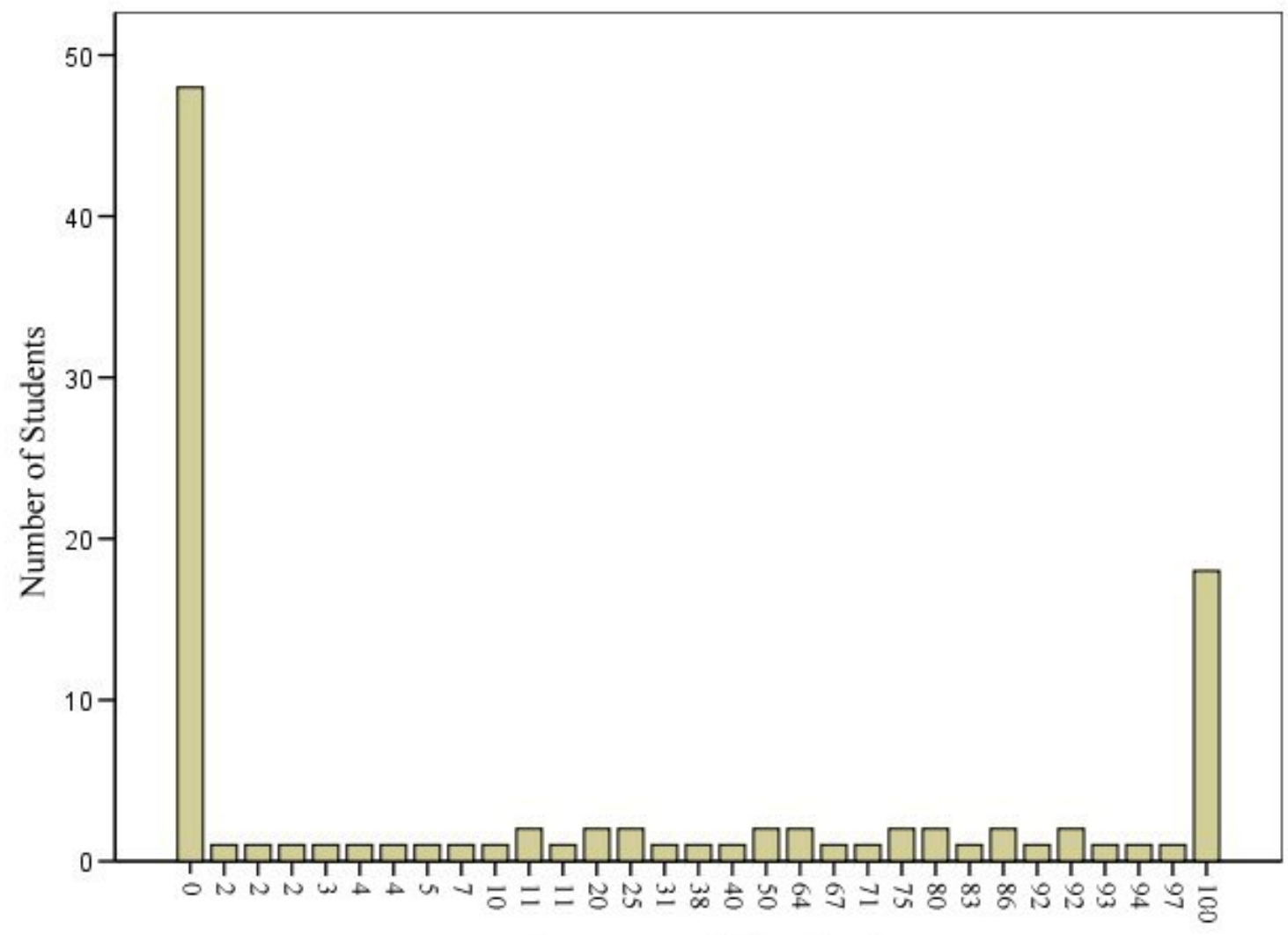

Percentage of Time Used

Figure 1. Safe Sex Score. Percentage of time condoms were used during actual intercourse events for the past three months as reported by the sexually active sample of students. 
The responses of sexually active participant's scores on the Sexual Sensation seeking scale revealed a mean of 25.4 with a standard deviation of 6.0.The possible score range for this measure was 11 to 44 . Sexually active participant's scores on the Sexual Self-Efficacy measure revealed a mean of 48.7 with a standard deviation of 8.3 . The possible score range for this measure was 0 to 100.

The researcher randomly assigned 1 of 5 behavioral scenarios to each participant, including sexually inactive participants. Two questions were asked following each behavioral scenario, "What would you most likely do in this situation? and "How confident are you that this would be your decision?”.

In scenario 1 the mean for what people would most likely do in the situation was 2.9 with a standard deviation of 1.0 . The mean confidence level for this scenario was 1.7 with a standard deviation of .77 (See table 1 for a description of all scenario score values). In scenario 2 the mean for what participants would most likely do was 2.7 with a standard deviation of 1.1. The mean confidence level for this scenario was 1.82 with a standard deviation of .80 . In scenario 3 the mean for what people would most likely do in the situation was 2.8 with a standard deviation of .83 . The mean confidence level for this scenario was 1.8 with a standard deviation of .65. The forth scenario revealed the mean for what people would most likely do in the situation at 3.1 with a standard deviation of 1.0. The mean confidence level for this scenario was 2.2 with a standard deviation of .72 . The final or $5^{\text {th }}$ scenario revealed a mean for what people would most likely do in this situation at 2.9 with a standard deviation of 1.2. The mean confidence level for this scenario 2.0 with a standard deviation of .95. 
The first hypothesis predicted that individuals exhibiting high sexual sensation seeking traits would have higher scores on sexual risk taking. A Pearson correlation coefficient revealed a positive and significant relationship, $r=0.358, \mathrm{p}<.001$ (See Table 3 for all correlation values of major variables). This hypothesis was supported; the participants that scored higher on the Sexual Sensation Seeking Scale also had higher scores on The Sexual Risk Measure.

The second hypothesis stated that individuals who score lower on sexual selfefficacy would score higher on sexual risk taking. This hypothesis was not supported; the results from this study did not find that sexual self-efficacy was related to sexual risk taking behavior.

The third hypothesis predicted that sexual sensation seeking would be negatively related to sexual self-efficacy. This hypothesis was not supported.

The rest of the hypotheses examined participant's answers on randomly assigned behavioral scenarios created to test how thought patterns and stress conditions affect people’s decisions to participate in sexual situations. Theses scenarios were based loosely based on Albert Bandura's definition of self-efficacy. One-way analyses of variance, were utilized to determine the significance of the following hypotheses.

The fourth hypothesis stated that those individuals who received a scenario with a high stress condition (Appendix K, Scenario I and II) would choose to participate in 
Table 3

Correlation Matrix of Major Variables (Sexually Active Subjects, $n=113$ )

\begin{tabular}{|l|l|c|c|l|l|l|}
\hline & & $\begin{array}{l}\text { Sexual Risk } \\
\text { Measure }\end{array}$ & $\begin{array}{l}\text { Number of } \\
\text { Partners }\end{array}$ & $\begin{array}{l}\text { SSSS } \\
\text { Total }\end{array}$ & SSE Total & $\begin{array}{l}\text { Drinking and } \\
\text { Drug use }\end{array}$ \\
\hline SSSS Total & Pearson Correlation & .358 & - & - & - & - \\
\hline SSE Total & Pearson Correlation & .087 & .097 & - & - & - \\
& $\mathrm{n}$ & 104 & 113 & & & \\
\hline Drinking & Pearson Correlation & .330 & .146 & .281 & - & - \\
and Drug use & $\mathrm{n}$ & 104 & 108 & 108 & & \\
\hline Sexual Risk & Pearson Correlation & 1 & .469 & .358 & .087 & - \\
Measure & $\mathrm{n}$ & 104 & 104 & 104 & 104 & \\
\hline Number of & Pearson Correlation & .469 & 1 & .312 & .097 & .146 \\
Partners & $\mathrm{n}$ & 104 & 113 & 113 & 113 & 108 \\
\hline
\end{tabular}


riskier sexual behavior than those receiving a low stress condition (Appendix K, Scenario III and IV). This hypothesis was not supported.

The fifth hypothesis stated that individuals receiving scenarios with self debilitating thought patterns (Appendix K, Scenario I and IV) would choose to participate in riskier sexual behavior than those receiving scenarios with self-encouraging thought patterns (Appendix K, Scenario II and III). This hypothesis was also not supported.

The final or sixth hypothesis predicted that there would be an interaction between stress and thought pattern conditions. Those who received both high stress and selfdebilitating thoughts (Appendix K, Scenario I) would choose to participate in the most risky sexual behaviors; this final hypothesis was not supported. There was no interaction between stress and thought pattern conditions.

Two additional relationships were explored pertaining to Zuckerman's theory of sensation seeking. Zuckerman (1994) believed that those high on sensation seeking would have reported more sexual partners and have higher levels of drinking and drug use. This study looked specifically at sexual sensation seeking and the numbers of partners recorded and at the recorded levels of drinking and drug use during sex.

A Pearson correlation was used to examine the relationship between sexual sensation seeking $(M=24.4, S D=6.0)$ and the number of sexual partners that participants recorded in the last three months $(M=1.73, S D=1.35)$. The Pearson correlation revealed a positive relationship at $r=0.469, \mathrm{p}<.001$. Those who scored high on the Sexual Sensation Seeking Measure tended to record a greater number of sexual partners than participants who scored low on this measure. A Pearson correlation also 
revealed a positive relationship between sexual sensation seeking and number of times drinking or drug happened during sex in the past three months $(M=7.6, S D=12.8)$ at $r$ $=0.330, \mathrm{p}<.001$. Those who scored higher on the Sexual Sensation Seeking Measure had used alcohol and drugs more often than those who scored low on the Sexual Sensation Seeking Measure. A Bon Ferroni type adjustment was made to check for inflated Type 1 errors because of multiple (5) correlations. Using alpha $=.01$ for each correlation, the overall alpha is .049 or below 0.05 . 


\section{DISCUSSION}

This study examined the relationship of sexual self-efficacy and sexual sensation seeking on sexual risk taking behavior in young adult college students. Six hypotheses regarding sexual self-efficacy, sexual sensation seeking and sexual risk taking were analyzed. The results of these finding were mixed and should be thoroughly explored in order to interpret their meaning.

An expected, correlation between sexual sensation seeking and high-risk sexual behavior was found. Participants who scored higher on the Sexual Sensation Seeking Scale also scored higher on the Sexual Risk Measure. One possible explanation for this behavior according to Zuckerman (1994) is that sex is a primary need and since the goal of sensation seeking behavior is to increase rather than decrease stimulation, sensation seekers are constantly seeking out activities that will increase stimulation despite the related consequences. Zuckerman's theory of sensation seeking also attributes risky sexual behavior to sensation seekers being less happy in sexually exclusive relationships, having more sexual partners, engaging in a greater variety of sexual behaviors, and having a more permissive attitude toward sex.

Others studies have sought to determine what mediates sensation seekers’ decisions to engage in high-risk activities including sexual risk. Research has suggested that persons who score higher on sensation seeking tend to evaluate high risk activities as less risky than persons who score lower on sensation seeking (Horvath \& Zuckerman, 1993; Hoyle, et al., 2000). High sensation seekers view the intense reward of instant 
gratification as outweighing the perceived risk. This might hold especially true in a sexual situation where STD, or AIDS risk, is not something that is always a consequence of a sexual encounter or might not be discovered until later. Sensation seekers in general show less concern about incurring a disease such as an STD or HIV (Fisher \& Misovich, 1990).

In this study sexual self-efficacy was not found to be related to sexual risk taking behavior. Participants who scored higher on the Sexual Self-Efficacy Scale did not score lower on the Sexual Risk Taking Measure as had been predicted. A possible explanation for the lack of this relationship could be that participants high on sexual self-efficacy might believe that they have the ability to abstain from risky sexual situations yet when faced with a real life challenging situation find it more difficult to follow through. Bandura (1997) recognizes that sometimes the difficulty of maneuvering through a real life sexual situation can sometimes override the best informed judgment. As many researchers have noted, there tends to be a large inconsistency between what people say they can do and what they actually do in a challenging sexual situation (Forsyth \&Carey, 1998; Rosenthal, et al., 1991).

Another interesting finding in self-efficacy research is that researchers found that young women who have more confidence to assert control in a sexual relationship might actually have increasing amounts of sexual activity, which doesn’t necessarily translate into taking preventative measures against STD’s (Seal, et al., 1997).

Research exploring the direct relationship between sexual self-efficacy and sexual sensation seeking at the time of this study was lacking scientific support. Although many 
studies acknowledged both constructs to apply to sexual risk taking, research looking at specifically how these two constructs affect each other or how they might mediate sexual risk taking is unclear at this time. In this study it was hypothesized that sexual sensation seeking would be negatively correlated with sexual self-efficacy. This hypothesis was unsupported. A possible explanation for these findings might be that these two constructs are unrelated; one might have high sexual self-efficacy and still score high on sexual sensation seeking or vice versa. Just because someone seeks out novel and complex sensations and experiences doesn't mean they don’t feel like they have control or motivation over their behavior or emotional environment.

Three behavioral scenarios based loosely on Albert Bandura’s definition of selfefficacy were also explored. Bandura acknowledged that the amount of stress in a situation coupled with other variables such as self-debilitating or self-encouraging thought patterns affect how much effort, control and confidence they perceive they have in a given situation.

It was hypothesized that those individuals who received a high stress condition would be more likely to choose to participate in risky sexual behavior than those receiving a low stress condition. It was also hypothesized that those receiving a selfdebilitating thought pattern would choose to participate in riskier sexual behavior than those receiving a scenario with a self-encouraging thought pattern. The last hypothesis predicted that those who received both high stress and self-debilitating thought patterns would choose to participate in the most risky sexual behaviors. None of the above mentioned hypotheses were supported. 
These unexpected results could have been due to the difficulty of recreating a sexual situation. It was predicted that using a scenario would help participants actually place themselves in a situation and recreate the complex process that young adults go through when faced with sexual decision-making. Although this could have been true, the researchers' hypotheses were not supported and rarely did any of the participants endorse unsafe sexual practices. There is a discrepancy between what participants said they would do in the scenario and what they reportedly do in their personal lives.

This discrepancy could be due to numerous factors including flawed measurement and faulty operationalization of sexual self-efficacy. Or it might be due to the fact that, although the scenario tried to mirror a real life sexual situation it might have been very difficult for participants to picture themselves in this scenario, which lacked personal investment in the decision making process. There are many different factors that come into play in a sexual situation, which may have not been apparent in the sexual scenarios. Forsyth and Carey (1998) acknowledge that a person's self-efficacious beliefs fluctuate depending on the perceived difficulty of enacting behaviors in a certain domain of functioning. It is a possibility that participants did not perceive these sexual situations as being difficult.

Factors that make sexual decision making difficult for a person are numerous and include levels of arousal, whether it's a new partner or former partner, past sexual history, whether a participant is intoxicated, and whether a partner is perceived as high or low risk (Murphy, et al., 2001). These scenarios did not incorporate all of these factors 
and might have been lacking the description necessary to mimic the complexity, difficulty, and personal challenges of sexual decision-making.

Two additional relationships were explored pertaining to sexual sensation seeking that provided interesting implications for future research. Zuckerman (1994) states that "high sensation seekers tend to engage in a greater variety of sexual behaviors with a greater number of partners than low sensation seekers” (p.144). He goes on to acknowledge that variety in partners and certain forms of sexual activity with the absence of protection leads to an increased risk of contracting sexually transmitted diseases. Zuckerman believes that it is the variety of sexual partners and varied sexual activity which puts people at risk for acquiring an STD although he state that those high on sensation seeking are not less likely to use contraception than low sensation seekers. A Pearson correlation supported Zuckerman's theory. There was a statistically significant positive relationship between numbers of reported sexual partners and sexual sensation seeking scores.

There have been numerous studies supporting the relationship of sensation seeking and drug use. People who scored higher on general measures of sensation seeking tend to record higher levels of drug and alcohol use than low sensation seekers. Zuckerman has also explored the relationship between sensation seeking, drug and alcohol use and sex. He found there to be a correlation between drugs and sex in both male and females who scored high on a general sensation seeking measure. In this study sexual sensation seeking was significantly and positively correlated with using alcohol and drugs during sex. Those who scored highly on sensation seeking reported more drug 
and alcohol use during sex than low sensation seekers. Both these findings support Zuckerman's theory of sensation seeking.

Limitations of the Study and Implications for Future Research

The participants in this study were one hundred and sixty seven undergraduate college students ages 18-25 from a state university in northern California, whose answers might not have been representative of a larger population. The majority of participants were Caucasian (79.6 \%), heterosexual (80\%), and female (73\%). These findings might not be descriptive of other types of samples. It would be recommended that a new study be conducted on a larger sample with a more diverse population.

A major limitation of this study was that both the sexual sensation seeking scale and the sexual self-efficacy scale are relatively new scales that haven't been widely used on a variety of populations. At the time of this study, research supporting the sexual selfefficacy scale was relatively limited. The sexual sensation seeking scale had been validated on mostly homosexual males and lacked consistency with heterosexual and female populations (Kalichman, et.al, 1994).

Although there has been much research concerned with risky sexual behavior it is still a very personal and controversial topic for many. The researcher warned participants that this study would contain material that might be sensitive would ask them to reflect on past sexual experiences. It should be noted that because of this a certain population of people might have shied away from participation in this survey. Therefore this study might have elicited participants who felt more comfortable with their sexuality and this 
might not be representative of others who might find this topic too confidential to explore in an online survey.

The complexity of exploring a topic that deals with sexual behavior makes it virtually impossible to use a measure other than a self-report measure. Ethical and practical concerns prevent the use of other ways to explore this topic. Reliance on selfreport measures always run the risk of response bias and might result in over reporting or under reporting behaviors. It is important to realize that participants might not have responded to this questionnaire with complete honesty.

It should be noted that precautions were taken in order to protect participant's confidentiality and make answering this survey as safe as possible. However, it s imperative to take into account that self report measures are not always the most reliable instruments.

There have been many studies that have sought to link self-efficacy to sexual risk taking behavior (Forsyth, \& Carey, 1998). Unfortunately, many of the results have been mixed and often very difficult to interpret. It was predicted that looking specifically at sexual self-efficacy and creating sexual scenarios in which participants would have to maneuver through difficult sexual decision-making would help alleviate some of these issues. Unfortunately, the hypotheses that looked at sexual self-efficacy and utilized behavioral scenarios were not supported.

Although some research has supported the use of behavioral scenarios (Murphy, et.al, 2002), these researchers took months to interview participants to create scenarios that were representative of difficult sexual situations in which they had been previously 
involved. The scenarios in this study were not pilot tested nor were they created specifically to model participants’ past experiences. This might have been a detriment to how generalizable these scenarios were to real life situations that participants had experienced. It also might have been appropriate to pilot the high stress and low stress conditions as well as the self-debilitating and self-encouraging thought patterns to make sure that these conditions were different enough to elicit distinct feelings from participants.

There was a large discrepancy between what participants said they would do in these behavioral scenarios and what they reportedly do in their personal lives. For example, in Figure 1, a very small percentage of participants actually used condoms $100 \%$ of the time and in fact the mean percentage was just around $30 \%$, suggesting that in actual sexual events condoms were not planned for or used regularly.

Self reports of much fewer risk behaviors than actually occurred may have been due to the influence of social desirability. The options that were given to participants as to what to do in these predicaments might have been to brief and obvious as to what was the "right answer". It is more socially acceptable to choose safe sex or to abstain from sex rather than choosing to have unsafe sex. Participants might have chosen what they thought was the socially desirable option whereas in a real life situation these answers wouldn't be quite as clear.

Although data was collected from participants who were over the age of 18, the researcher chose to look specifically at the data from participants between the ages of 1825 because this was consistent with much of the research looking at college aged 
populations. It would be recommended that in future research that all the data be analyzed to see if there were any differences in the sexual activity of this older age group.

These findings may have important implications as to what factors contribute to young adult's decision to engage in unsafe sexual practices and the future research on campaigns aimed at increasing safe sex on college campuses.

In this study sexual sensation seeking was shown to be linked to not only sexual risk taking behavior but also to the numbers of partners and drinking and drug use during sex. More research on sexual sensation seeking might help to provide more clues as to what determines young people to engage in unsafe sexual behavior. Research has shown that people high on sensation seeking tend to evaluate risky activity as less risky than other groups. Many of the sexually active participants in this study were found to be high risk for contracting HIV and AIDS yet only $13.3 \%$ reported themselves as believing they were at risk. Campaign strategies aimed at college students might need to address these issues more at length and explore why young people in general feel as though they are not personally at risk.

Drug and alcohol use during sex was also very prevalent in this study, especially for those who scored high on sensation seeking. Sexual decision-making is difficult enough and being under the influence of drugs and alcohol may alter people's decision to engage in safe sexual behavior even more. Future research should pay special attention to the effects of drugs and alcohol especially pertaining to sexual decision-making and incorporate this into campaign and intervention techniques. 
Some literature on sensation seeking and message manipulation suggests that it might be valuable to use different campaign strategies targeted at both high and low sensation seekers on topics such as risky sex and drug and alcohol use because they respond to stimuli differently. Sheer and Cline (1995) suggest that sensation seekers tend to require stronger, novel and highly arousing messages to hold their attention whereas low sensation seekers tend to respond better to more familiar and less intense stimulation.

Although sexual self-efficacy was not found to have a significant relationship to sexual risk taking in this study it still may be a viable factor in sexual decision-making. Future research should attend to the difficulty in operationalizing this construct and take into account the complexity of sexual decision-making.

The behavioral scenarios used in this study were not found to have significant relevance to the likelihood of engaging in sexual risk taking behaviors. Using scenarios tailored to information from participants about what they consider to be a difficult sexual situation might provide new information on how to better understand why young adults participate in risky sexual behavior even though they endorsed having safe sex or abstaining from sex in the scenarios that were provided.

Finally, tailoring specific interventions or campaigns that incorporate the findings from this study might prove useful in attempting to reach out to this age group. More information on what is undesirable or difficult about having safe sex and the perceived invulnerably that young adults have towards getting infected with STD's and HIV needs to be addressed. Intervention strategies aimed at the use of alcohol and other drugs that 
might impair ones capacity to practice safe sex should be focused on, especially on college campuses where these issues are very common. 


\section{REFERENCES}

Arnold, P., Fletcher, S., \& Farrow, R. (2002). Condom use and psychological sensation seeking by college students. Sexual and Relationship Therapy,17 (4), 355-365.

Bandura, A. (1990). Perceived self-efficacy in the exercise of control over AIDS infection. Evaluation and Program Planning, 13(1), 9-17.

Bandura, A. (1997). Self-efficacy: The exercise of control. New York: W. H. Freeman and Company.

Catania, J. A., Coates, T. J., Stall, R., Turner, H., Peterson, J., Hearst, N., Dolcini, M. M., Hudes, E., Gagnon, J., Wiley, J., \& Groves, R. (1992). Prevalence of AIDSrelated risk factors and condom use in the united states. Science, 258, (13), 11011106.

Centers for Disease Control and Prevention: HIV/AIDS Surveillance Report (2003). Washington, DC: Centers for Disease Control and Prevention.

Centers for Disease Control and Prevention: HIV/AIDS Surveillance Report (1997). Washington, DC: Centers for Disease Control and Prevention.

Cooper, L. M. (2002). Alcohol use and sexual behavior among college students and youth: Evaluating the evidence. Journal of Studies on Alcohol, March, (14), 101117. 
Cooper, L. M., Shapiro, C. M., \& Powers, A. M. (1998). Motivations for sex and risky sexual behavior among adolescents and young adults: A functional perspective. Journal of Personality and Social Psychology, 75 (6), 1528-1558.

Cooper, L. M., Wood, P. K., Ocrutt, H. K., Austin, A. (2003). Personality and the predisposition to engage in risky or problem behaviors during adolescence. Journal of Personality and Social Psychology, 84 (2), 390-410.

Dodge, B., Reece, M., Cole, S. L., \& Sandfort, T. G. M. (2004) Sexual compulsivity among heterosexual college students. The Journal of Sex Research, 41 (4), 343350.

Donenberg, G. R., Emerson, E., Bryant, F. B., \& King, S. (2006). Does substance use moderate the effects of parents and peers on risky sexual behavior. AIDS Care, 18 (3), 194-200.

Donohew, L., Zimmerman, R., Cupp, P. S., Novak, S., Colon, S., \& Abell, R. (2000). Sensation seeking, impulsive decision- making, and risky sex: Implications for risk taking and design of interventions. Personality and Individual Differences, 28 (6), 1079-1091.

Fisher, J. D., Fisher, W. A., Misovcich, S.J., Kimble, D.L., \& Malloy, T. E. (1996). Changing AIDS risk behavior: Effects of an intervention emphasizing AIDS risk reduction information, motivation, and behavioral skills in a college population. Health Psychology, 15 (2), 114-123. 
Fisher, J. D., \& Misovich, S. J. (1990). Evolution of college students’ AIDS related behavioral responses, attitudes, knowledge, and fear. AIDS Education and Prevention, 2 (4), 322-337.

Forsyth, A .D., \& Carey, M. P. (1998). Measuring self-efficacy in the context of HIV risk reduction: Research challenges and recommendations. Health Psychology, 17 (6), 559-568.

Gray, J. A. (1990). Brain systems that mediate both emotion and cognition. Cognition and Emotion, 4 (3), 269-288.

Gullette, D.L \& Lyons, M.A. (2005). Sexual sensation seeking, compulsivity and HIV risk in college students. Journal of Community Health Nursing, 22 (1), 47-60.

Henderson, V. R., Hennesey, M., Barrett, D. W., Curtis, B., McCoy-Roth, M., Trentacoste, N., \& Fishbein, M. (2005). When risky is attractive: Sensation seeking and romantic partner selection. Personality and Individual Differences, $38(2), 311-325$.

Horvath, P. \& Zuckerman, M. (1993). Sensation seeking, risk appraisal, and risky behavior. Journal of Individual Differences, 14 (1), 41-52.

Hoyle, R.H., Fejfar, M.C., \& Miller, J.D. (2000). Personality and sexual risk taking: A quantitative review. Journal of Personality, 68 (6), 1203- 1231. 
Kalichman, S. C., \& Cain, D. (2004). A prospective study of sensation seeking and alcohol use as predictors of sexual risk behaviors among men and women receiving sexually transmitted infection clinic services. Psychology of Addictive Behaviors, 18 (4), 367-373.

Kalichman, S. C., Johnson, J.R., Adair, V., Rompa, D., Multhauf, K., \& Kelly, J. A. (1994). Sexual sensation seeking: Scale development and predicting AIDS- risk behavior among homosexually active men. Journal of Personality Assessment, 62 (3), 385-397.

Kalichman, S. C., \& Rompa, D. (1995). Sexual sensation seeking and sexual compulsivity scales: Reliability, validity, and predicting HIV risk behavior. Journal of Personality Assessment, 65 (3), 586-601.

Kalichman, S. C., Simbayi, L. C., Kaufman, M., Cain, D., Cherry, C., Jooste, S., \&Mathiti, V. (2005). Gender attitudes, sexual violence, and HIV/AIDS risk among men and women in cape town, south africa. The Journal of Sex Research, $42(4), 299-305$.

Katz, E.C., Fromme, K. \& D’Amico, E.J. (2000). Effects of outcome expectancies and personality on young adults’ illicit drug use, heavy drinking and risky sexual behavior. Cognitive Therapy and Research, 24 (1), 1-22.

Kelly, G. F. (2001). Sexuality Today: The human perspective, seventh edition. New York: McGraw- Hill Higher Education. 
Kelly, J. A., \& Kalichman, S. C. (1995). Increased attention to human sexuality can improve HIV-AIDS prevention efforts: Key research issues and directions. Journal of Consulting and Clinical Psychology, 63 , (6), 907-918.

Lewis, J. E., \& Malow, R .M. (1997). HIV/ AIDS risk in heterosexual college students: A review of a decade of literature. Journal of American College Health, 45 (4), $147-$ 159.

Murphy, D.A., Stein, J.A, Schlenger, W., Maibach, E. \& National Institute of Mental Health Multisite HIV Prevention Trial Group (2001). Conceptulizing the multidimensional nature of self-efficacy: Assesment of situational context and level of behavioral challenge to maintain safer sex. Health Psychology, 20 (4), 281-290.

Newcomb, M. D., \& McGee, L. (1991). Influence of sensation seeking on general deviance and specific problem behaviors from adolescence to young adulthood. Journal of Personality and Social Psychology, 61 (4), 614-628.

Peterson, J. L., \& Diclemente, R. J. (2000). Handbook of HIV prevention. New York: Kluwer/ Plenum Publishers.

Prince, A., \&Bernard, A. L. (1998). Sexual behaviors and safer sex practices of college students on a computer campus. Journal of American College Health, 47 (1), 1121. 
Rosenthal, D., Moore, S. \& Flynn, I. (1991). Adolescent self-efficacy, self esteem and sexual risk taking. Journal of Community and Applied Social Psychology, 1, 7788.

Rosenthal , D. \& Moore, S. (1993). Venturesomeness, impulsiveness and risky behavior among older adolescents. Perceptual and Motor Skills. 76, 98-109.

Seal, A., Michichello, V. \& Omodei, M. (1997). Young women’s sexual risk taking behavior: re-visiting the influences of sexual self-efficacy and sexual self-esteem. International Journal of STD \& AIDS, 8(3), 159-165.

Sheer, V. C., \& Cline, R. J. (1995). Individual differences in sensation seeking and sexual behavior: Implications for communication intervention for HIV/ AIDS prevention among college students. Health Communication, 7(3), 205-223.

Wulfert, E. \& Wan, C. K. (1995). Safer sex intentions and condom use viewed from a health belief, reasoned action and social cognitive perspective. The Journal of Sex Research, 32 (4) 299-311.

Zuckerman, M. (1994). Behavioral expressions and biosocial bases of sensation seeking. New York: Cambridge University Press.

Zuckerman , M. \& Kuhlman, D. M. (2000).Personality and risk-taking : Common biosocial factors. Journal of Personality, 68 (6), 999-1029. 


\section{APPENDIX A \\ E-MAIL TO ADMINISTRATIVE ASSISTANTS}

Hello, My name is Amelia Coulter and I'm in my 2nd year of the counseling psychology master's program here at HSU. As part of my graduate thesis I've composed an online survey. I'm trying to announce participation in this online survey to undergraduates in certain majors via e-mail. I've chosen some of the largest major's at this school so that I can get the most accurate well rounded data possible. I was wondering if you'd consider sending out this e-mail to all your undergraduate students in your department to announce my research, so that interested students could participate. This project has been approved by the IRB and given expedited review because the participants will be over

age 18, it will be confidential and it will pose little or no risk to participants. Please let me know whether you agree to send this out or if you have any questions. I'd be happy to give you any other information you feel you need. I'm sending a copy of the e-mail I would like to go out to students following this so you can take a look at it.

Thank you so much for your time, Amelia Coulter 


\section{APPENDIX B \\ E-MAIL TO POTENTIAL PARTICIPANTS}

My name is Amelia Coulter and I'm a Master's student in the Counseling Psychology Program. I'm working on research concerning the sexual behaviors of students here at Humboldt State University as part of my Master's Thesis. I would appreciate if you would take the time to contribute to this research by filling out this brief anonymous survey. There is no extra credit provided for participation in this survey, but participation is greatly appreciated and will contribute to research on the sexual behavior of college students. This survey contains sexually explicit material. If you feel that you may be offended by it please do not consent to participate in this project. Please do not answer these questions if you are under the age of 18 If you are over 18 and would like to participate or learn more about this project, please click on the following link. This survey is voluntary, if at any time you wish to withdraw from participating you may do so with absolutely no consequences. Your completion and submission of the survey acknowledges your consent to participate.

Please click on the following link to access this survey http://www.humboldt.edu/ pssurvey/s.sb/

If you do participate in this survey, and in the unlikely event that it raises some concerns for you, here is a list of phone numbers you may call to receive some guidance for your concerns:

-North Coast AIDS Project (NorCap) 268-2108

Free and anonymous HIV testing

-National Crisis Hotline 1-800-784-2433

On Campus Referrals

-Davis House Clinic 826-3921

Sliding Scale fee's

-Counseling and Psychological Services (CAPS) 826-3236

Free to students

If you have any further questions please contact:

Amelia Coulter, M.A Student, primary researcher ajc46@humboldt.edu

Lou Ann Wieand, 826-5263

Psychology Department at Humboldt State

Donna Schafer/ Carla Douglas at the IRB 826-3949

Thank you for your time, Amelia Coulter 


\section{APPENDIX C SURVEY OF SEXUAL BEHAVIORS}

You, a student at Humboldt State University, are being asked to volunteer to participate in a study of sexual behavior. There is no extra credit provided for participation in this survey, but participation is greatly appreciated and will contribute to research on the sexual behavior of college students. This survey contains sexually explicit material. If you feel that you may be offended by it please do not consent to participate in this project. Please do not answer these questions if you are under the age of 18. This survey is voluntary, if at any time you wish to withdraw from participating you may do so with absolutely no consequences. Your completion and submission of the survey acknowledges your consent to participate. It should take you about 20 minutes to complete the questionnaire.. Also, do not insert your name anywhere as you are answering the questions. If you choose to participate, please answer this questionnaire as honestly and as completely as possible. All information collected will remain anonymous. When you submit your answers, they will go to a Web server that will send them anonymously to an email address as numerals. Although the results of this study may be published at some time, at no time will any identifying information be able to be used. You are at liberty to withdraw from this project and to discontinue answering at any time. If you copy down this web address, you will be able to get a full summary of students' answers here by Summer, 2006. If you have any questions prior to that time, please feel free to call Dr. Wieand in the Psychology Department at Humboldt State at 826-5263, Donna Schafer/Carla Douglas at the IRB (826-3949) or Amelia Coulter, the primary researcher at ajc46@humboldt.edu.

If you do participate in this survey, and in the unlikely event that it raises some concerns for you, here is a list of phone numbers you may call to receive some guidance for your concerns:

-North Coast AIDS Project (NorCap) 268-2108

Free and anonymous HIV testing

-National Crisis Hotline 1-800-784-2433

On Campus Referrals:

-Davis House Clinic 826-3921

Sliding Scale fee's

-Counseling and Psychological Services (CAPS) 826-3236

Free to students

\begin{tabular}{|c|}
\hline $\begin{array}{c}\text { I am } 18 \text { or older } \\
\text { and } \\
\text { would like to take } \\
\text { the survey }\end{array}$ \\
\hline
\end{tabular}

I am under 18

or

do not want to

take the survey 


\section{APPENDIX D \\ SURVEY OF SEXUAL BEHAVIORS}

You, a student at Humboldt State University, are being asked to volunteer to participate in a study of sexual behavior. It should take you about 20 minutes to complete the questionnaire. Please do not answer these questions if you are under the age of 18. Also, do not insert your name anywhere as you are answering the questions. If you choose to participate, please answer this questionnaire as honestly and as completely as possible. All information collected will remain anonymous. When you submit your answers, they will go to a Web server which will send them anonymously to an email address as numerals. Although the results of this study may be published at some time, at no time will any identifying information be able to be used. You are at liberty to withdraw from this project and to discontinue answering at any time. If you copy down this web address, you will be able to get a full summary of students' answers here by Summer, 2006. If you have any questions prior to that time, please feel free to call Dr. Wieand in the Psychology

Department at Humboldt State at 826-5263.

\section{Part I}

1. My age is

2. My gender is

C. Female

C. Male

3. Select one of the groups below that best describes yourself:
C Asian, Asian-American
C Black, African-American
Latin, Hispanic, Mexican, Mexican-American, Chicano, Spanish Heritage
C Native American Indian
C Alaskan Native
Filipino or Pacific Islander
$\checkmark$ White, Caucasian
$C$ Other (specify) 
Appendix D, continued

4. Select one of the terms below that best describes how you think of yourself:

$C$ heterosexual

$\mathrm{C}$ homosexual, gay, lesbian

$C$ bisexual

$C$ Other (specify)

5. Are you currently:

$C$ single, never been married

$C$ married or living with a partner

$\checkmark$ divorced or separated, not living with a partner

$\checkmark$ widowed, not living with a partner

$C$ Other (specify)

6. I feel that I am at risk for contracting HIV (Human Immunodeficiency Virus)

$C$ Yes

$C$ No 


\section{APPENDIX E \\ SURVEY OF SEXUAL BEHAVIORS \\ PART II}

Directions: Please read the following statements and rate whether or not the statements reflect your own experiences, thoughts or feelings. Indicate the response that best fits your reaction to the statement.

Not at all like me

1
Somewhat like me

2
Often like me

3
Very much like me

4

\footnotetext{
$\begin{array}{llll}1 & 2 & 3 & 4\end{array}$

$\odot \subset C \sim$ 1. I like the "uninhibited" sexual encounters.

$C \quad C \quad C \quad$ 2. The physical sensations are the most important thing about having sex.

$C \subset C S$ 3. I enjoy the sensation of intercourse without a condom.

$C \quad C \quad C \quad C \quad$ 4. My sexual partners probably think I'm a "risk taker".

$\ulcorner\subset \backsim$ 5. When it comes to sex, physical attraction is more important to me than how well I know the person.

$\subset \subset C r$ 6. I enjoy the company of "sensual" people.

$\subset \subset C \backsim$ 7. I enjoy watching "X-rated" videos.

$C \quad C \quad C \quad C$ 8. I have said things that were not exactly true to get people to have sex with me.

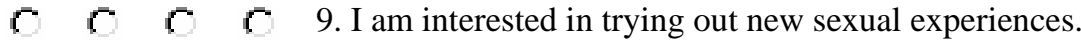

$C \quad C \quad C \quad C$ 10. I feel like exploring my sexuality.

$\subset \subset \subset \subset$ 11. I like new and exciting sexual experiences and sensations.
} 


\section{APPENDIX F \\ SURVEY OF SEXUAL BEHAVIORS \\ PART III}

Directions: Please read the following scenario carefully. Proceed in answering the questions following the scenario as if you were really faced with this situation. Please answer as honestly as possible.

You and your friends are at party. You're all having a good time, enjoying yourselves, when you lock eyes with someone from across the room. They walk over and you start talking. You're both very attracted to one another. The night is getting late and people are starting to "pair off". You and your friends invite a few people back to your place including the person you've been talking to. Once back at your place you two slip away and things immediately start to get heated. You begin kissing and touching and it feels like things are starting to lead towards having sex. You realize you don't have any condoms and it appears like you're going to have to be the one to bring up using them. When you ask if they have a condom, they kindly reply, "No, I don't have one either. What would you feel most comfortable doing now?" You're still feeling concerned and are taking all your feelings into account. You know that this is your decision to make and that your partner will understand.

1. What would you most likely do in this situation? Mark one of the following choices.

$\checkmark$ I would probably have penetrative sex without a condom.

I would probably not have sex.

$\checkmark$ I would probably continue "hookin up" but not have penetrative sex.

I would probably ask my partner to purchase a condom and then have sex.

$\checkmark$ I would probably purchase a condom and then have sex.

2. How confident are you that this would be your decision
C Extremely
C Very
C 50:50
C Somewhat
C Not at All 


\section{APPENDIX G \\ SURVEY OF SEXUAL BEHAVIORS \\ PART IV}

These are questions about your sexual behavior. All answers are confidential. Please answer the questions as openly and honestly as possible by selecting the response that fits you best.

1. Do you consider yourself sexually active? That is, do you have genital sexual relationships (sexual intercourse, oral-genital sex or anal sex) with another person or persons on a regular basis?

$C$ Yes

$C$ No

2. If you answered yes to \#1, would you define your relationship as monogamous (sexually exclusive)?

$\odot$ Yes

3. If you answered yes to \#1, how often did you do the following in the past three months: (Enter approximate number of times on the line next to the question).

Vaginal intercourse with a condom.

Vaginal intercourse without a condom.

Oral-genital sex with a condom.

Oral-genital sex without a condom.

Anal sex with a condom.

Anal sex without a condom.

Sex while drinking or doing drugs.

4. How many partners have you had sexual relationships with in the past year (12 months)?

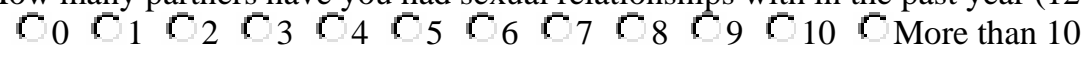

5. I have told a partner that I would not have intercourse without a condom.

$\begin{array}{ccccc}\text { Never } & \text { Seldom } & \text { Sometimes } & \text { Often } & \text { Always } \\ C & C & C & C & C\end{array}$

6. My partner would be upset if I asked that a condom be used during intercourse.

$\begin{array}{ccccc}\text { Never } & \text { Seldom } & \text { Sometimes } & \text { Often } & \text { Always } \\ C & C & C & C & C\end{array}$


Appendix G, continued

7. I have been tested for HIV (the AIDS virus).

$C$ Yes

8. I have a close personal friend who has been infected with the AIDS virus.

$C$ Yes

$C$ No

9. Knowledge about AIDS has affected my sexual behavior.

$C_{\text {No }}$

10. I have asked my partner(s) about the number of sexual partners he/she had before having sex with me.

$C$ With all partners.

$C$ With some partners.

$C$ Did not discuss it.

11. I have discussed with my partner(s) about the number of past sexual partners I have had.

$C$ With all of them.

$C$ With some of them.

$C$ Did not discuss it.

12. I inject drugs into my veins or under my skin.

$C$ Yes

$C$ No

13. I have injected drugs into my veins or under my skin.

$C$ Yes

$\checkmark$ No

14. My partner injects drugs into his/her veins or under his/her skin.

$C$ Yes

$C$ No

15. My partner has injected drugs into his/her veins or under his/her skin.

$C$ Yes

$\odot$ No

16. I have had sex with someone who has injected drugs into his/her veins or under his/her skin.

$\odot$ Yes 


\section{APPENDIX H \\ SURVEY OF SEXUAL BEHAVIORS \\ PART V}

The following items are intended to measure people's opinions about the use of condoms. There are no right or wrong responses to any of these statements. Please respond even if you are not sexually active or have never used (or had a partner who used) condoms. In such cases indicate how you think you would feel in such a situation.

Please read each of the following statements and indicate by selecting the number of the response that best fits your feeling about the statement.

For example, if you agree with a certain statement, select 4. If you strongly disagree, select 1 and so forth.

$\begin{array}{ccccc}\text { Strongly Disagree } & \text { Disagree } & \text { Undecided } & \text { Agree } & \text { Strongly Agree } \\ 1 & 2 & 3 & 4 & 5\end{array}$

\footnotetext{
$\begin{array}{lllll}1 & 2 & 3 & 4 & 5\end{array}$

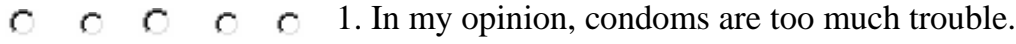

$\ulcorner\subset \subset \subset \subset$ 2. Condoms are unreliable.

$\ulcorner\subset \subset \subset \quad$ 3. The neatness of condoms, for example, no wet spot on the bed, makes them attractive.

$\subset \subset \subset \subset \subset$ 4. I see the use of a condom as adding to the excitement of foreplay if the female partner helps the male put it in place.

$\subset \subset \subset \subset \subset$ 5. I would be willing to try a condom, even if I have never used one before.

$c \quad c \quad c \quad c \quad c \quad 6$. There is no reason why a woman should be embarrassed to suggest a condom.

$\subset \subset \subset \subset \subset$ 7. Women think men who use condoms show concern and caring.

$\odot \odot \odot \odot \quad \odot \quad 8$. I intend to try condoms.

$\subset \subset c c c$. I think proper use of a condom can enhance sexual pleasures.

$\ulcorner\subset \subset \subset \subset$ 10. Many people make use of the condom as an erotic part of foreplay.

$\subset \subset \subset \subset \subset$ 11. All things considered, condoms seem safer to me than any other form of contraception except abstinence.

$\subset \subset \subset \subset \subset$ 12. I just don't like the idea of using condoms.

$\odot \subset \subset \subset \subset$ 13. I think condoms look ridiculous.

$\odot \subset \subset \subset c$ 14. Condoms are inconvenient.

$\subset \subset \subset \subset \subset$ 15. I see no reason to be embarrassed by the use of condoms.

$\subset \subset \subset \subset \subset$ 16. Putting a condom on an erect penis can be a real sexual turn-on.

$\ulcorner\subset \subset \subset \subset$ 17. Condoms are uncomfortable.

$\odot \subset c \quad c \quad \odot$ 18. In my opinion, condoms are too much trouble.

$\ulcorner\subset \subset \subset \subset$ 19. Using a condom makes sex unenjoyable.

$\odot \odot \odot \sim c$ 20. I would avoid using condoms if at all possible.

$\ulcorner\subset c \quad c \quad c$ 21. I would be comfortable suggesting that my partner and I use a condom.

$\subset \subset \subset \subset \subset$ 22. Condoms ruin the sex act.

$\subset \subset \subset \sim c \quad$ 23. Condoms are uncomfortable for both partners.

$\subset \subset \subset \subset \subset 2$ 24. Women think men who use condoms are jerks.

$\subset \subset \subset \subset \quad c 25$. The idea of using a condom doesn't appeal to me.
} 
Appendix H, continued

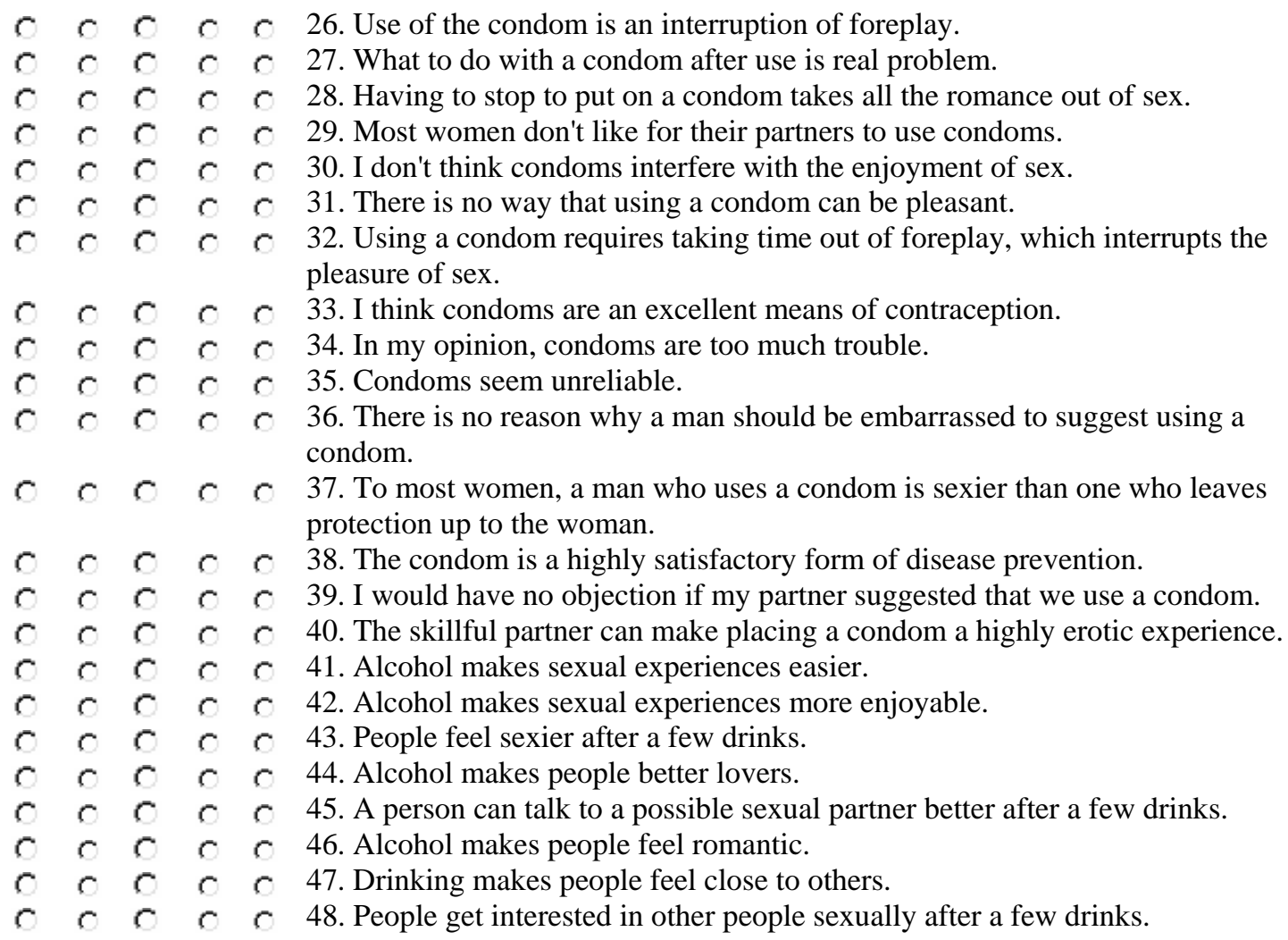




\section{APPENDIX I \\ SURVEY OF SEXUAL BEHAVIORS \\ PART VI}

Directions: Please indicate whether or not you feel like you could do each activity. Mark "Yes" if you feel like you could do the activity and "No" if you feel like you couldn't do the activity. For those activities that you answer "Yes" to, rate your degree of confidence in your ability to do the activity with the following scale:

$\begin{array}{ccccc}\text { Very Uncertain } & \text { Somewhat } & \text { Neither Certain nor } & \text { Somewhat Certain } & \text { Very Certain } \\ 1 & \text { Uncertain } & \text { Uncertain } & & \\ 1 & 2 & 3 & 4 & 5\end{array}$

No

C 1. Refuse a sexual advance by your partner.

\begin{tabular}{|c|c|c|c|}
\hline & & Kes & \\
\hline 1 & 2 & 3 & 4 \\
\hline 0 & $c$ & $\mathrm{c}$ & $c$ \\
\hline 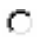 & $c$ & $c$ & $c$ \\
\hline 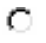 & $c$ & $c$ & $c$ \\
\hline$\sigma$ & $c$ & $c$ & $c$ \\
\hline 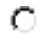 & $c$ & $c$ & $c$ \\
\hline 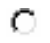 & $c$ & $c$ & $c$ \\
\hline 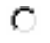 & $c$ & $c$ & $c$ \\
\hline$C$ & $c$ & $c$ & $c$ \\
\hline$r$ & $c$ & $c$ & $c$ \\
\hline$c$ & $c$ & $c$ & $c$ \\
\hline$r$ & $c$ & $c$ & $c$ \\
\hline 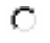 & $c$ & $c$ & $c$ \\
\hline$r$ & $c$ & $c$ & $c$ \\
\hline 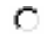 & $c$ & $c$ & $c$ \\
\hline$c$ & $c$ & $c$ & $c$ \\
\hline 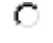 & $c$ & $C$ & $c$ \\
\hline 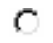 & $c$ & $c$ & $c$ \\
\hline$r$ & $c$ & $c$ & $c$ \\
\hline & $c$ & $c$ & $c$ \\
\hline
\end{tabular}

2. Have a sexual encounter without feeling obliged to have intercourse.

c 3. Put a condom on an erect penis.

c 4. Initiate sexual activities.

C 5. Discuss using condoms and/or other contraceptives with a potential partner.

c 6. Ask a potential partner to wait if precautions are not available at the time.

C 7. Carry condoms around with you "in case".

C 8. Control your sex urges while under the influence of alcohol or drugs.

C 9. Meet your own sexual needs by masturbation.

c 10. Discuss with a partner use of condoms for AIDS protection when other means of contraception are already being used.

c 11. Choose when and with whom to have sex.

C 12. Tell your partner how to treat you sexually.

c 13. Refuse to do something sexually which you don't feel comfortable about.

c 14. Be able to buy condoms/contraceptives.

c 15. Discuss precautions with a doctor or health professional.

$c \quad 16$. Admit being inexperienced to your sexually experienced peers.

$c$ 17. Reject an unwanted sexual advance from someone other than your partner, e.g.

c 18. Watch sexually explicit movies without embarrassment.

C 19. Ask someone other than your partner for a date.

c 20. Ask your partner to provide the sexual stimulation you require.

$c \mathrm{C} C \mathrm{C}$

\section{Submit Survey Clear Fields}




\section{APPENDIX J \\ SURVEY OF SEXUAL BEHAVIORS \\ CONCLUSION}

Please Print this sheet and keep for yourself.

Thank you for participating in this study.

If any questions in the survey have raised concerns about your feelings or behaviors, here is a list of resources that may address those concerns.

North Coast AIDS Project (NorCAP)

Humboldt County Department of Health and Human Services - public health branch

529 I Street, Eureka

Free and anonymous HIV testing

Monday through Thursday 1:00 to 4:00 pm

Drop in basis

268-2108

National Crisis Hotline 1-800-784-2433

On Campus Referrals

Davis House Clinic

House 81

826-3921

dlh7004@humboldt.edu

Sliding Scale Fees

Counseling and Psychological Services (CAPS)

Health Center 205

826-3236

Free to students

If you would like a summary of the group results, they should be available by this summer, 2006.

Please copy this URL to gain access to the results

at that time. www.humboldt.edu/ pssurvey/ssb

Lou Ann Wieand

Psychology Department at Humboldt State

Amelia Coulter, M.A. student

ajc46@humboldt.edu

This survey was reviewed and approved by

Donna Schafer/ Carla Douglas at the IRB

826-3949 
APPENDIX K

SCENARIO I

High Stress/ Self Debilitating Thought Conditions

You and your friends are at party. You're all having a good time, enjoying yourselves, when you lock eyes with someone from across the room. They walk over and you start talking. You're both very attracted to one another. The night is getting late and people are starting to "pair off". You and your friends invite a few people back to your place including the person you've been talking to. Once back at your place you two slip away and things immediately start to get heated. You begin kissing and touching and it feels like things are starting to lead towards having sex. You realize you don't have any condoms or protection with you and it appears like you're going to have to be the one to bring up using something. When you ask if they have a condom or protection with them, they sharply reply, "No, I'm safe. We don't need a anything." You're still feeling concerned and unsure but now you're worried you're killing the mood if you bring it up again and you're fearful that you're offending your partner. You don't want them to think you're not interested.

1.) What would you most likely do in this situation? Mark one of the following choices.

I would probably have penetrative sex without protection.

_ I would probably not have sex.

- I would probably continue "hooking up" but not have penetrative sex.

I would probably ask my partner to purchase protection and than have sex.

I would probably purchase protection and than have sex

2.) How confident are you that this would be your decision?

_ Extremely

- Very

- 50:50

Somewhat

Not at All 
Appendix K, continued

\section{Scenario II}

High Stress/ Self Encouraging Thought Conditions

You and your friends are at party. You're all having a good time, enjoying yourselves, when you lock eyes with someone from across the room. They walk over and you start talking. You're both very attracted to one another. The night is getting late and people are starting to "pair off". You and your friends invite a few people back to your place including the person you've been talking to. Once back at your place you two slip away and things immediately start to get heated. You begin kissing and touching and it feels like things are starting to lead towards having sex. You realize you don't have any condoms or protection with you and it appears like you're going to have to be the one to bring up using something. When you ask if they have a condom or protection with them, they sharply reply, "No, I'm safe. We don't need a anything." You're still feeling concerned and are taking all your feelings into account. You know that this is your decision to make and that your partner will understand.

1.) What would you most likely do in this situation? Mark one of the following choices.

I would probably have penetrative sex without protection.

I would probably not have sex.

_ I would probably continue "hooking up" but not have penetrative sex.

_ I would probably ask my partner to purchase protection and than have sex.

I would probably purchase protection and than have sex

2.) How confident are you that this would be your decision?

_ Extremely

Very

- 50:50

_ Somewhat

_ Not at All 
Appendix K, continued

Scenario III

Low Stress/ Self Encouraging Thought Conditions

You and your friends are at party. You're all having a good time, enjoying yourselves, when you lock eyes with someone from across the room. They walk over and you start talking. You're both very attracted to one another. The night is getting late and people are starting to "pair off". You and your friends invite a few people back to your place including the person you've been talking to. Once back at your place you two slip away and things immediately start to get heated. You begin kissing and touching and it feels like things are starting to lead towards having sex. You realize you don't have any condoms or protection with you and it appears like you're going to have to be the one to bring up using something. When you ask if they have a condom or protection with them, they kindly reply, "No, I don't have anything either." What would you feel most comfortable doing now? You're still feeling concerned and are taking all your feelings into account. You know that this is your decision to make and that your partner will understand.

1.) What would you most likely do in this situation? Mark one of the following choices.

I I would probably have penetrative sex without protection.

_ I would probably not have sex.

I I would probably continue "hooking up" but not have penetrative sex.

_ I would probably ask my partner to purchase protection and than have sex.

_ I would probably purchase protection and than have sex

2.) How confident are you that this would be your decision?

_ Extremely

- Very

- 50:50

Somewhat

_ Not at All 
Appendix K, continued

Scenario IV

Low Stress/ Self Debilitating Thought Conditions

You and your friends are at party. You're all having a good time, enjoying yourselves, when you lock eyes with someone from across the room. They walk over and you start talking. You're both very attracted to one another. The night is getting late and people are starting to "pair off". You and your friends invite a few people back to your place including the person you've been talking to. Once back at your place you two slip away and things immediately start to get heated. You begin kissing and touching and it feels like things are starting to lead towards having sex. You realize you don't have any condoms or protection with you and it appears like you're going to have to be the one to bring up using something. When you ask if they have a condom or protection with them, they kindly reply, "No, I don't have anything either." What would you feel most comfortable doing now? You're still feeling concerned and unsure but now you're worried you're killing the mood if you bring it up again and you're fearful that you're offending your partner. You don't want them to think you're not interested.

1.) What would you most likely do in this situation? Mark one of the following choices.

I would probably have penetrative sex without protection.

I would probably not have sex.

_ I would probably continue "hooking up" but not have penetrative sex.

I would probably ask my partner to purchase protection and than have sex. I would probably purchase protection and than have sex

2.) How confident are you that this would be your decision?

_ Extremely

Very

50:50

Somewhat

Not at All 
Appendix K, continued

\section{Scenario V}

\section{Control Condition}

You and your friends are at party. You're all having a good time, enjoying yourselves, when you lock eyes with someone from across the room. They walk over and you start talking. You're both very attracted to one another. The night is getting late and people are starting to "pair off". You and your friends invite a few people back to your place including the person you've been talking to. Once back at your place you two slip away and things immediately start to get heated. You begin kissing and touching and it feels like things are starting to lead towards having sex. You realize you don't have any condoms or protection with you and it appears like you're going to have to be the one to bring up using something.

1.) What would you most likely do in this situation? Mark one of the following choices.

_ I would probably have penetrative sex without protection.

I would probably not have sex.

I would probably continue "hooking up" but not have penetrative sex.

_ I would probably ask my partner to purchase protection and than have sex.

_ I would probably purchase protection and than have sex

2.) How confident are you that this would be your decision?

_ Extremely

Very

- 50:50

_ Somewhat

_ Not at All 